\title{
A pragmatic continuum level model for the prediction of the onset of keyholing in laser powder bed fusion
}

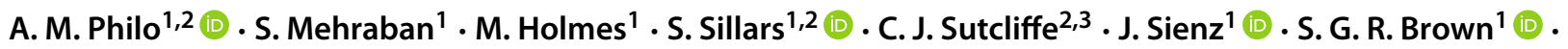 \\ N. P. Lavery ${ }^{1}$ iD
}

Received: 21 June 2018 / Accepted: 24 September 2018 / Published online: 7 November 2018

(C) The Author(s) 2018

\begin{abstract}
Laser powder bed fusion (L-PBF) is a complex process involving a range of multi-scale and multi-physical phenomena. There has been much research involved in creating numerical models of this process using both high and low fidelity modelling approaches where various approximations are made. Generally, to model single lines within the process to predict melt pool geometry and mode, high fidelity computationally intensive models are used which, for industrial purposes, may not be suitable. The model proposed in this work uses a pragmatic continuum level methodology with an ablation limiting approach at the mesoscale coupled with measured thermophysical properties. This model is compared with single line experiments over a range of input parameters using a modulated yttrium fibre laser with varying power and line speeds for a fixed powder layer thickness. A good trend is found between the predicted and measured width and depth of the tracks for $316 \mathrm{~L}$ stainless steel where the transition into keyhole mode welds was predicted within $13 \%$ of experiments. The work presented highlights that pragmatic reduced physics-based modelling can accurately capture weld geometry which could be applied to more practical based uses in the L-PBF process.
\end{abstract}

Keywords Additive manufacturing - Laser powder bed fusion · Modelling · Keyhole-mode laser melting · 316L stainless steel

\section{Nomenclature}

$\rho \quad$ Density

$C_{p} \quad$ Specific heat capacity

$T \quad$ Temperature

$\kappa \quad$ Thermal conductivity

$\alpha \quad$ Thermal diffusivity

$t \quad$ Time

$\hat{n} \quad$ Unit normal to surface

$q_{v} \quad$ Volumetric energy input

$q \quad$ Irradiated heat flux

A. M. Philo

adam.philo@swansea.c.uk

1 College of Engineering, Swansea University, Bay Campus, Crymlyn Burrows, Swansea, SA1 8EN, UK

2 Renishaw plc, Additive Manufacturing Products Division, Brooms Road, Stone Business Park, Stone, Staffordshire, ST15 0SH, UK

3 Department of Engineering, University of Liverpool, Brownlow Hill, Liverpool, L69 3GH, UK
$P \quad$ Laser power

$\sigma \quad$ Laser spot size

$r_{x} \quad$ Local laser radius in $\mathrm{x}$-direction

$r_{y} \quad$ Local laser radius in y-direction

$h \quad$ Heat transfer coefficient

$T_{0} \quad$ Ambient temperature

$L_{t} \quad$ Layer thickness

$\tau_{L} \quad$ Optical thickness

$\tau_{Z} \quad$ Dimensionless local layer thickness

$d_{p} \quad$ Particle diameter

$\beta \quad$ Extinction coefficient

$\rho_{t} \quad$ Tap density

$\rho_{s} \quad$ Sample density

$Z \quad$ Density of water

$\kappa_{p} \quad$ Powder thermal conductivity

$\kappa_{s} \quad$ Solid thermal conductivity

$C_{p_{p}} \quad$ Powder specific heat capacity

$C_{p_{s}} \quad$ Solid specific heat capacity

$\rho_{p} \quad$ Powder density

$\rho_{s} \quad$ Solid density

$e_{t} \quad$ Exposure time 


$\begin{array}{ll}p_{d} & \text { Point distance } \\ \nu & \text { Effective line speed } \\ d & \text { Penetration depth } \\ A & \text { Material absorptivity } \\ T_{b} & \text { Material boiling temperature } \\ T_{m} & \text { Material melting temperature } \\ \Delta H & \text { Enthalpy change } \\ h_{s} & \text { Enthalpy at melting }\end{array}$

\section{Introduction}

Additive manufacturing (AM) is a rapidly developing process with origins in rapid prototyping. It is attracting end-users in aerospace, automotive, medical and other sectors. Several variations of this processes have been developed, such as electron beam freeform fabrication $\left(E B F^{3}\right)$, wire + arc and laser powder bed fusion (L$\mathrm{PBF}$ ). This work concerns L-PBF which is otherwise known as selective laser melting (SLM), selective laser sintering (SLS), or direct metal laser sintering (DMLS). L-PBF allows for the fabrication of small intricate components from melting or sintering of a metal powder, using a high power laser creating a three-dimensional object on a layerby-layer basis. In addition, L-PBF provides a useful tool for creating fully dense parts across a range of metals but still contains challenges which need to be overcome [1-3].

A range of physical phenomena occur in the L-PBF processes which take place over a wide range of spatial and temporal scales. Length scales range from nanometres in terms of the condensates of metal vapour, to micrometres in terms of the laser beam and particles sizes and finally to centimetres/metres in terms of distortions and residuals stresses acting on full components. Time scales range from days in terms of build times to microseconds in terms of laser interaction time with the powder. This large range in scales makes it very difficult, if not impossible due to current computational capabilities, to model all physical aspects inherent within the L-PBF process. L-PBF is also a developing process which is not yet fully understood. Experimental testing at such small spatial and temporal scales can be very difficult and is usually expensive. This is where simulation and modelling can play a crucial role in understanding the effects of process parameters on the final condition of the part. In general, there are two levels of modelling in metal additive manufacturing. Modelling at the mesoscopic scale; on the scale of the powder $(\mu \mathrm{m})$ considering energy absorption into the powder, melt pool characteristics, fluid flow and granular flow effects [4]. Such modelling typically aims to predict defects such as porosity and surface roughness. Alternatively, macroscale (cm) modelling is applied on the scale of the part. This typically involves thermal or energy source modelling over larger representative volume elements to calculate residual stresses in the part or determine distortion or build failure.

The increased commercial use of L-PBF is challenged by processability issues such as slow lead times and quality issues such as part failure due to distortion or reduced mechanical properties due to part porosity. The majority of research is focused on understanding the effects of process parameters to reduce or avoid these problems. In this work, two key issues with respect to part quality of L-PBF manufactured parts are highlighted. Firstly, reduced mechanical properties due to porosity, contamination or microstructure modification (due to potentially alternating thermal cycles) must be considered [5-7]. These factors concern parts which can be built but which have been unintentionally manufactured in such a way that their mechanical properties are not optimal. Secondly, part failures may be due to distortion, cracking or interlayer delamination. Numerical modelling can be used for improved fundamental understanding of the process and as a design tool to understand the effect of process input parameters.

In L-PBF processes, a laser beam is used as the energy source where a large proportion of the energy is reflected due to the nature of the powder beds. For example, the absorptivity value for $316 \mathrm{~L}$ stainless steel (SS) is around 0.33 , meaning only $33 \%$ of the energy delivered to the powder bed is absorbed into the material. Conventionally in most models, the laser intensity is described as a Gaussian distribution at the surface of the material where the absorption can also vary as a function of powder depth. For the absorption of energy, many previous models use a surface flux boundary condition for energy deposition as most of the energy is absorbed and reflected here. This is often the case for $2 \mathrm{D}$ models $[8,9]$ and $3 \mathrm{D}$ simplified physics models $[10,11]$.

Gusarov and Smurov [12] extended this Gaussian distribution of laser intensity distribution as a function of non-dimensional powder depth. They model radiation transfer in which the powder bed is modelled as a packed bed of monodispersed opaque spheres. They show that the absorbance of the powder bed with large optical thickness is independent of powder morphology and porosity and they present equations for laser absorptivity as a function of optical thickness for a powder of the same material on a substrate. This absorptivity approach was adopted by Wits et al. [13].

For more comprehensive 3D models, volumetric energy sources are adopted. Ray tracing models [14], which calculate the path of single photons through a system have been implemented for a more comprehensive distribution of laser energy in these modelling approaches [15]. These models can give a more accurate distribution of laser energy when modelling on the level of the powder particles. 
Previous research using experimental analysis of single line tracks produced in L-PBF show the quality of manufactured parts strongly depends on the nature of the single laser tracks produced. This has been carried out for a range of metallic alloys, both ferrous and non-ferrous where it is noted that input parameters are not directly translational from material to material [16]. Yadroitsev et al. [17] study the effects of power and scanning velocities on different alloy compositions. They identify stability zones, where the single laser track is continuous with no break up and unstable zones containing break ups of the track. Also, if the laser moves too fast this can give rise to the balling effect $[18,19]$. This can be categorised by the Plateau-Rayleigh instability criterion for metal powders [17].

Laser welding shares some characteristics of L-PBF and can provide insight into certain types of behaviour. In laser welding, there are two distinct modes: keyhole and conduction modes. A keyhole weld is characterised by a deep penetrating weld which is produced from hydrodynamic instabilities, Marangoni forces and vaporisation recoil pressures [20, 21]. A conduction mode weld on the other hand produces higher quality welds where heat transfer is governed predominantly by heat conduction and generally forms a circular weld profile [22, 23].

In general welding, experimental and simulation-based research of these modes has been undertaken. This includes general experimental observation of the process [24, 25], models of melting and solidification [26] and complex models including vaporisation and mass transfer which are important in the development of keyhole zones [27-30]. Zhou et al. [31] give an overview of the fundamentals of keyhole formation in welding processes including keyhole formation due to recoil pressures, heat transfer and fluid flow. Also, Svenungsson et al. [32] give a review of keyhole welding modelling in the laser welding process.

Generally, to capture different weld regimes and geometries requires high-fidelity physics-based numerical models. These could cover the range of physical phenomena inherent in the L-PBF process but are computationally expensive. To the authors' knowledge, there is as yet little evidence to suggest that simplified models can capture weld pool geometry to a high level of accuracy.

In this work, a pragmatic continuum level model is developed and compared with experimental results. The model is based around the heat transfer equation without incorporating fluid or gas phase transport, but includes an ablating limiting methodology and the use as-measured thermo-physical properties by adopting the energy absorption technique of Gusarov and Smurov [12]. The model is compared with experimental single lines created using a $400 \mathrm{~W}$ ytterbium modulated laser on a Renishaw AM400 machine for a range of input parameters. These lines are then analysed and measurements taken of the weld height, width and depth, as well as line continuity and weld mode (keyhole or conduction). The term 'weld' is used here to describe the 'weld bead' nature of the melted and re-solidified material along the single line track of the laser.

\section{Computational model}

The L-PBF thermal evolution is modelled as a heat transfer process including material ablation. The 3D Fourier heat conduction equation is solved by using an explicit and transient finite difference solution. The 3D Fourier heat conduction equation can be written as:

$\rho(T) C_{p}(T) \frac{\partial T(t)}{\partial t}=\kappa(T)\left(\frac{\partial^{2} T}{\partial x^{2}}+\frac{\partial^{2} T}{\partial y^{2}}+\frac{\partial^{2} T}{\partial z^{2}}\right)+q_{v}$

where $\rho$ is the density $\left(\mathrm{kgm}^{-3}\right), C_{p}$ is the specific heat capacity $\left(J K^{-1}\right), T$ is the temperature $(\mathrm{K})$ and $\kappa$ is the thermal conductivity $\left(W m^{-1} K^{-1}\right)$ in a Cartesian coordinate system and $t$ is time (s). This is then discretised using a Forward-time Central-space (FTCS) explicit finite difference solution. As the FTCS scheme is explicit and is conditionally stable, the Courant-Friedrichs-Lewy (CFL) condition for a maximum time-step size is defined by the following to calculate the time step size

$\Delta t=\frac{\frac{1}{6} \Delta x_{i}^{2} \rho C_{p}}{\kappa}$

The thermophysical properties are a function of temperature and the spatial resolutions in all directions are potentially variable. Therefore, the model uses the minimum spatial resolution and the minimum density and specific heat capacity values coupled with the maximum thermal conductivity value to ensure stability throughout the domain. A schematic of the domain of the single line simulations is show in Fig. 1.

The domain length $D_{L}$ was set to $2.24 \mathrm{~mm}$ (32 beam widths) to ensure that a steady state solution of the melt pool was calculated. A steady-state solution in this case is defined as the situation where the weld width and depth no longer change as the solution progresses. The domain width $D_{W}$ and substrate thickness $s_{t}$ were set as $1.12 \mathrm{~mm}$ to not affect the solution. The grid size was kept uniform throughout the substrate where $\Delta_{x} S=\Delta_{y} S=\Delta_{z} S$ which are grid sizes in the $\mathrm{x}, \mathrm{y}$ and $\mathrm{z}$ direction on the substrate respectively. Within the powder layer $\Delta_{x} P=\Delta_{x} S$, and $\Delta_{y} P=\Delta_{y} S$ where $\Delta_{z} P$ was discretised by at least 10 elements. $\Delta_{x} P, \Delta_{y} P$ and $\Delta_{z} P$ correspond to the grid size in the powder layer in the $\mathrm{x}, \mathrm{y}$ and $\mathrm{z}$ direction, respectively. 
Fig. 1 Outline of domain parameters used in simulations

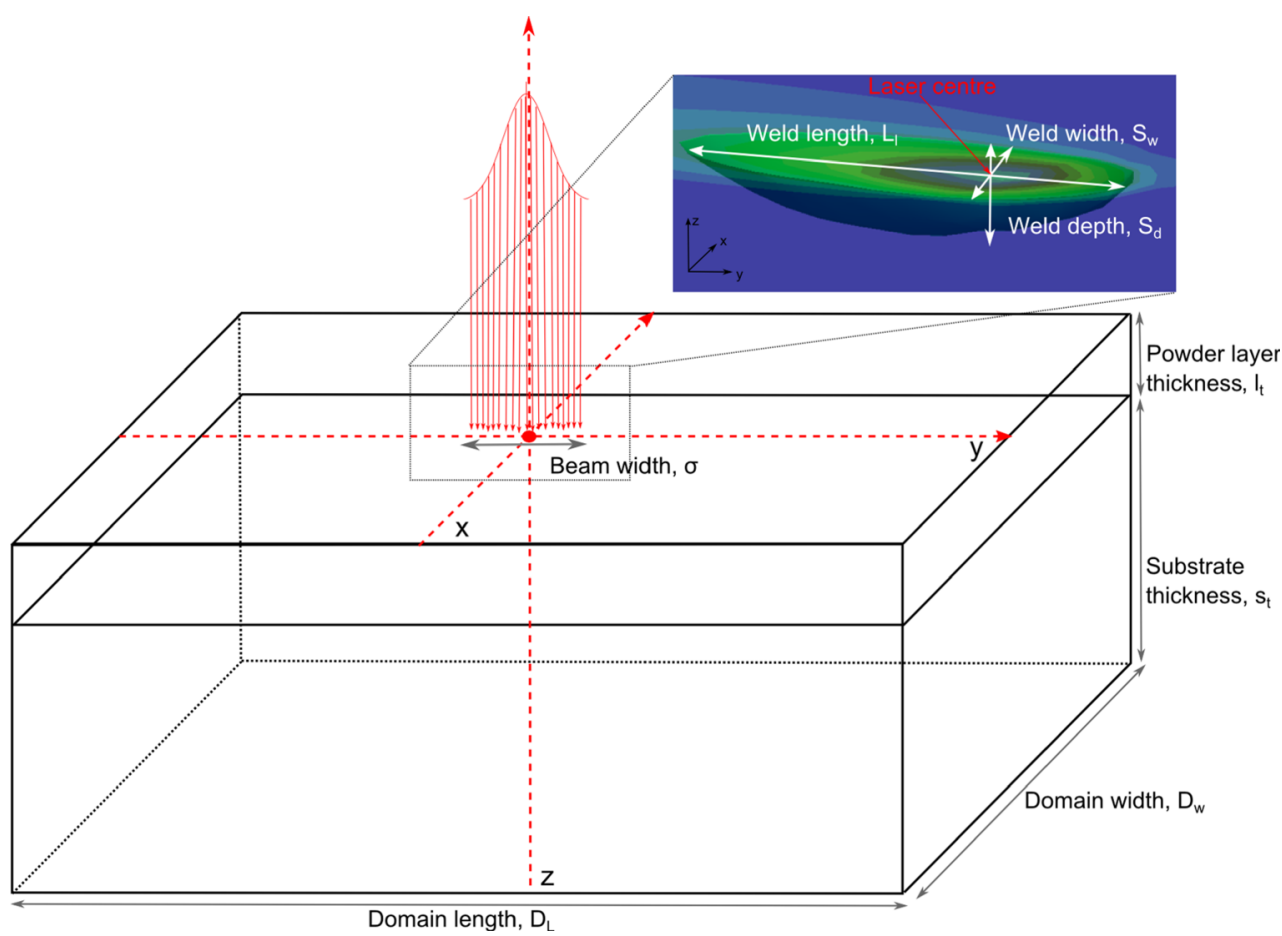

The $\Delta_{x}$ was chosen so that at least 5 nodes are contained within the laser radius to ensure sufficient discretisation of the laser. This gave a total of 8,704,000 grid elements within the domain.

\subsection{Energy absorption}

For the boundary domain, insulated Dirichlet boundary conditions are defined on all surfaces apart from the top surface which is defined by an irradiated heat flux.

$-\kappa \frac{\partial T}{\partial z} \hat{n}=q(r)$

where $\hat{n}$ is the unit normal to the surface and $q(r)$ is the laser irradiated energy defined by a Gaussian distribution:

$q(r)=\frac{(1-\omega) P}{\pi \sigma^{2}} e^{\frac{-\left(r_{x}^{2}-r_{y}^{2}\right)}{2 \sigma^{2}}}$

where $\omega$ is a material defined reflectivity value, $P$ is the laser power $(\mathrm{W}), r_{x}, r_{y}$ are the radial distances from the centre of the laser beam $(m)$ in the $x$ and $y$ coordinate respectively and $\sigma$ is the radius of the laser $(m)$. Heat loss at the surface is defined as:

$-\kappa \frac{\partial T}{\partial z} \hat{n}=h\left(T-T_{0}\right)-\omega \sigma_{S B}\left(T^{4}-T_{0}^{4}\right)$

where $h$ is the heat transfer coefficient $\left(h=50 \mathrm{Wm}^{-2} \mathrm{~K}^{-1}\right)$, $T_{0}$ is the ambient temperature and $\sigma_{S B}$ is the StefanBoltzmann constant $\left(\sigma_{S B}=5.68 \times 10^{-8} \mathrm{Wm}^{-2} \mathrm{~K}^{-4}\right)$

In addition, the interaction of the laser beam with the powder particles penetrates through pores into the depth of the powder layer. The following approach for laser penetration into the powder bed is adopted from Gusarov and Smurov [12]. The irradiated energy flux through the powder thickness $L_{t}$ is described by the sum of the directed radiation, the reflected radiation and the scattered radiation:

$$
\begin{aligned}
q= & \frac{\omega a}{(4 \omega-3) D}\left[\left(1-\omega^{2}\right) e^{-\tau_{L}}\left((1-a) e^{-2 a \tau_{z}}+(1+a) e^{2 a \tau_{z}}\right)-\right. \\
& -\left(3+\omega e^{-2 \tau_{L}}\right)\left((1+a-\omega(1-a)) e^{2 a\left(\tau_{L}-\tau_{z}\right)}\right. \\
& \left.\left.+[1-a-\omega(1+a)] e^{2 a\left(\tau_{z}-\tau_{L}\right)}\right)\right] \\
& -\frac{3(1-\omega)\left(e^{-\tau_{z}}-\omega e^{\tau_{z}-2 \tau_{L}}\right)}{4 \omega-3}
\end{aligned}
$$

In which

$$
\begin{aligned}
D= & (1-a)(1-a-\omega(1+a)) e^{-2 a \tau_{L}} \\
& -(1+a)(1+a-\omega(1-a)) e^{2 a \tau_{L}}
\end{aligned}
$$

where $\omega$ is the reflectivity of the material and $a=\sqrt{1-\omega}$, $\tau_{L}=\beta L_{t}$ is the optical thickness and $\tau_{z}=\beta z_{b}$ is the dimensionless local powder bed depth where. Assuming that the powder bed consists of spherical particles with diameter $d_{p}$ the extinction coefficient $\beta$ is defined as

$\beta=\frac{3}{2} \frac{1-\epsilon}{\epsilon} \frac{1}{d_{p}}$

where $\epsilon$ is the powder layer porosity. For this work $d_{p}=30 \mu m, \epsilon=0.5$ and $\omega=0.67$. Figure 2 shows the laser penetration profile as a function of powder bed depth. 


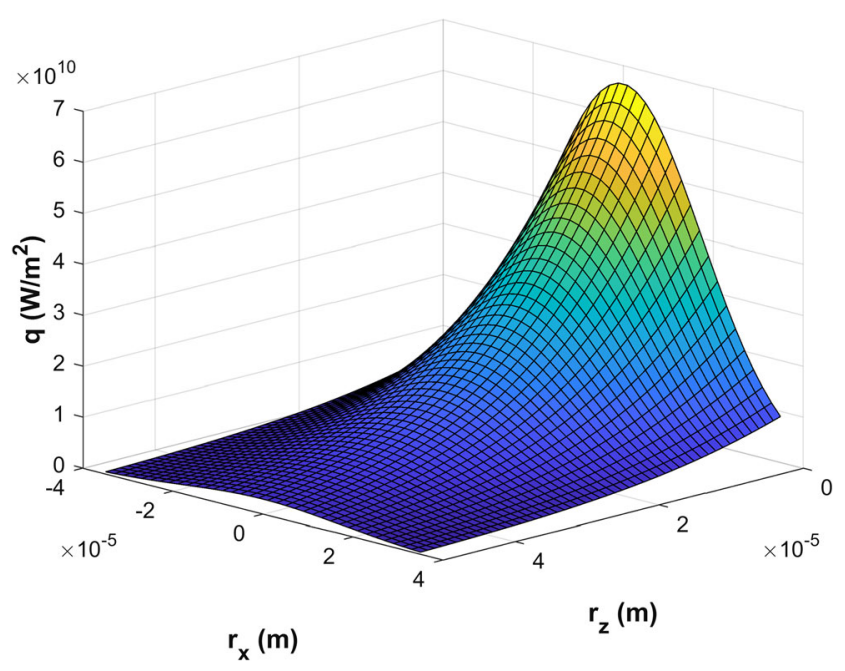

Fig. 2 Laser penetration profile for a $200 \mathrm{~W}$ laser with a $70 \mu \mathrm{m}$ beam width of a $50 \mu \mathrm{m}$ powder bed thickness. The z-direction shows penetration depth; the $\mathrm{x}$-axis shows axial coordinate

\subsection{Material ablation}

The L-PBF process experiences vaporisation of liquid material due to the highly localised heat source. When the molten pool reaches the vaporisation temperature, a phase transformation occurs where a metal gas is produced; the rapidly moving evaporated materials expand and generate a recoil pressure on the molten pool. Low levels of recoil pressure can cause the molten pool to be flattened, whilst high recoil pressure causes the removal of molten material by melt expulsion and creates a metal plume consisting of metal vapour and plasma. The level of depression of the melt pool surface will depend on the equilibrium balance between the hydrodynamic forces of the melt pool and the pressure of the expanding gas [33]. To approximate these effects, namely the level of depression of the melt pool, an ablation limiting model is used. This approach calculates the temperatures at locations within the domain and if the temperature at a node is above that of the vaporisation temperature for a material then that node is redefined as vaporised and the surface of the melt pool is lowered.

Figure 3 a outlines the simulation domain, where a cross section of a single exposure with time steps is shown in Fig. 4. Figure $3 \mathrm{~b}$ shows the location of the cross sections (directly through the centre of a laser exposure transverse to laser scanning direction) used in Figs. 4 and $3 \mathrm{c}$ the cross section (parallel to the laser direction) through the centre of the completed solidified track demonstrating the steady state solution of the weld depth.

In Fig. 4, there are 5 times steps through a $600 \mu s$ laser exposure using $200 \mathrm{~W}$. The left column in Fig. 4 shows the temperature distribution through the cross section. Time $\mathrm{t}=0$ $\mu s$ is at a pause between the laser exposures and $\mathrm{t}=120 \mu \mathrm{s}$
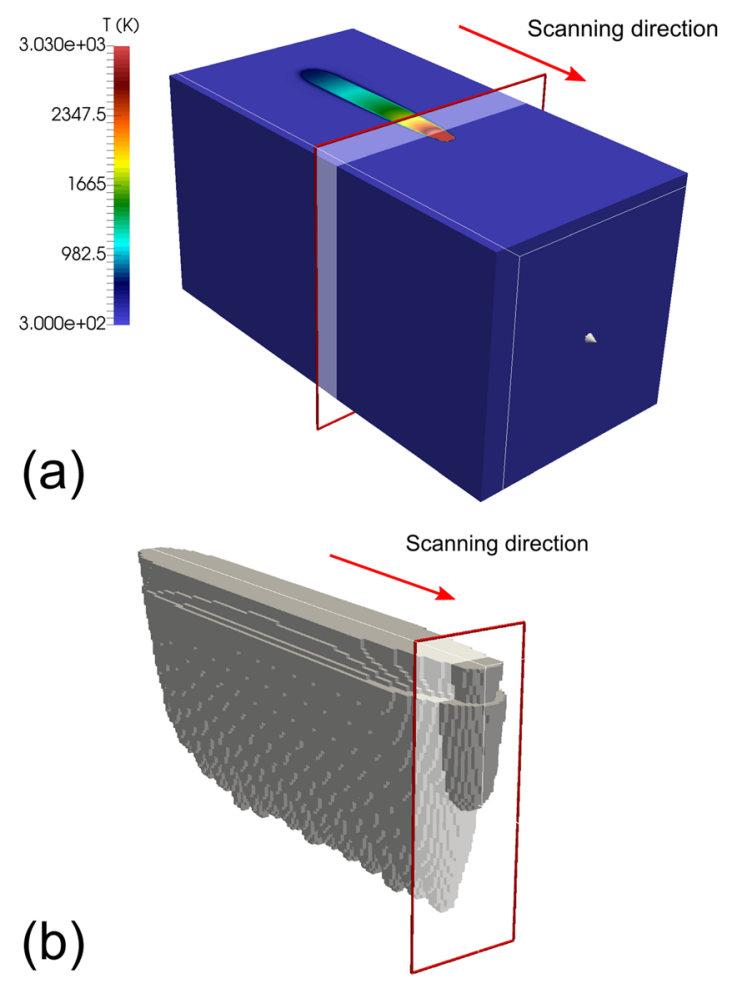

(b)

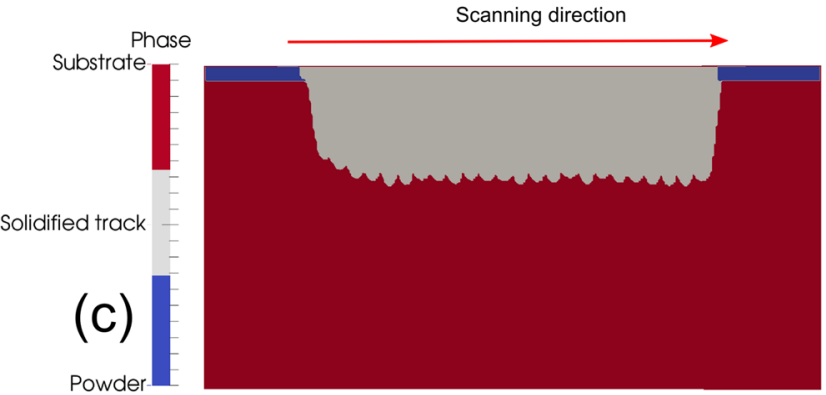

Fig. 3 a Simulation domain and temperature profile for Fig. 4 and b outline of cross sections through weld profile and c cross-section through the centre of a weld track parallel to the direction of scanning

is slightly after an exposure where the temperature observed is residual heat from the previous exposure at roughly 1500 $\mathrm{K}$. The equivalent heat flux is shown in the right column. At $\mathrm{t}=120 \mu \mathrm{s}$ in the regions where the temperature was calculated to be above the boiling point, $3273 \mathrm{~K}$, the energy deposition at the surface of the melt pool is then lowered. When the calculated temperature is below the boiling point, the heat flux is then applied at this location. The same can be observed for subsequent time steps as the laser exposure continues. It can be observed that the walls surrounding the depression are slightly under the boiling temperature which is a phenomenon described in [33]. It is this ablation modelling technique which gives rise to the simulated deep penetration in the model associated with keyhole welds.

In addition, an example of the ablation model for a low and high exposure deposition with the ablation model 
Fig. 4 Left; temperature distributions right; 3D weld profile with heat flux. For time steps within an exposure time of $600 \mu s$ using laser power $200 \mathrm{~W}$ and effective line speed as $0.1 \mathrm{~m} / \mathrm{s}$
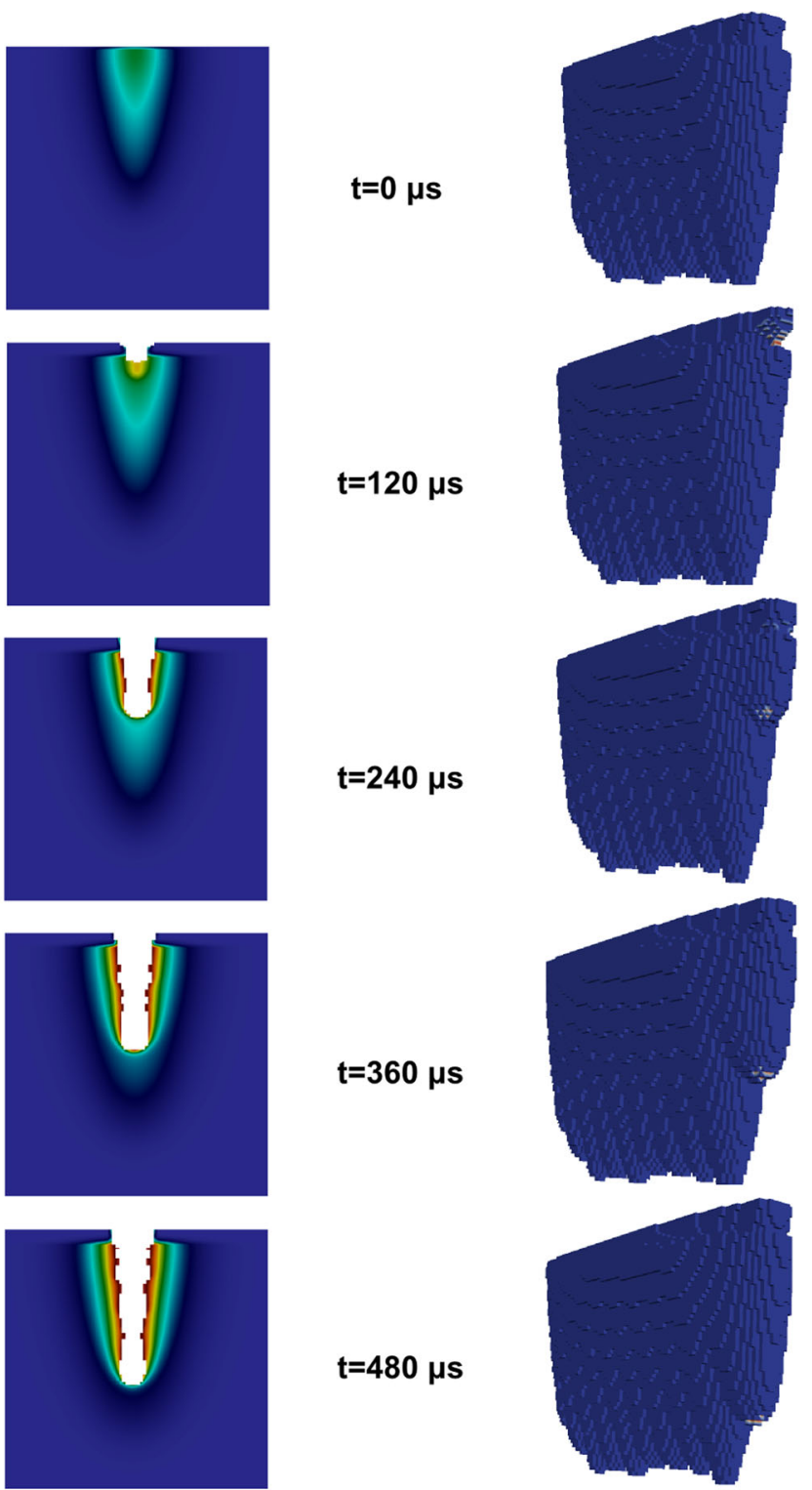

$\mathrm{T}(\mathrm{K})$
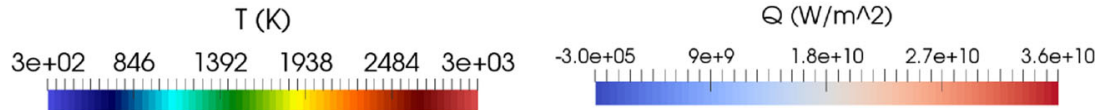

present in simulations and not present is shown in Fig. 5 highlighting the effect and need of the ablation model on simulation results.

From Fig. 5 when using a lower exposure time without using the ablation model, there is practically zero penetration into the powder bed and hence zero melting. With the ablation model present for lower exposures, the laser penetrates the powder bed and creates a melt pool. For higher exposure times, where a keyhole weld is expected, keyholing is only captured when using the ablation penetration model. Without the ablation model for higher exposure times there is penetration but not as one would expect within a keyhole regime weld. For all subsequent simulations, the ablation model is present.

\section{Thermophysical material properties of $316 \mathrm{~L}$ stainless steel}

The material characterised in this work is $316 \mathrm{~L}$ SS (both powder and solid material) where thermophysical properties data are all temperature dependent. The powder was produced by Sandvik Osprey with powder size distributions $\operatorname{Dx}(10), \operatorname{Dx}(50)$ and $\operatorname{Dx}(90)$ values of $19.28 \mu \mathrm{m}, 29.99$ 

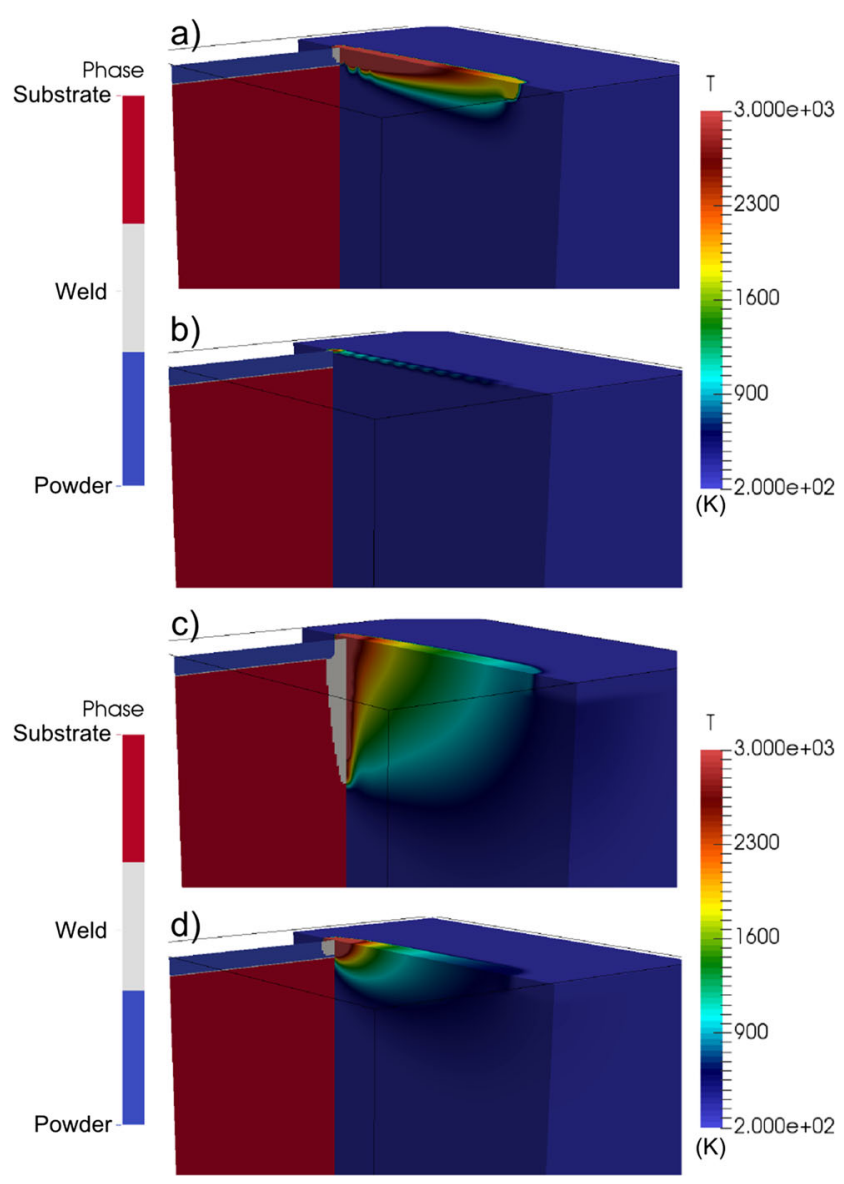

Fig. 5 Comparison of temperature and weld profiles with the ablation model present and not. (a) $200 \mathrm{~W}$ and $0.7 \mathrm{~m} / \mathrm{s}$ Ablation model present (b) $200 \mathrm{~W}$ and $0.7 \mathrm{~m} / \mathrm{s}$ ablation model not present (c) $200 \mathrm{~W}$ and 0.1 $\mathrm{m} / \mathrm{s}$ Ablation model present (d) $200 \mathrm{~W}$ and $0.1 \mathrm{~m} / \mathrm{s}$ Ablation model not present

$\mu m$ and $46.01 \mu m$, respectively and composition shown in Table 1. The chemical composition of the 316L powder presented is as stated from the supplier [34]. The powder morphology is shown in Fig. 6.

\subsection{Thermal diffusivity and density}

The thermal diffusivity of solid 316L SS was measured using a Netzsch Laser Flash Analyser (LFA) 457. A solid $2.5 \times 10 \times$ $10 \mathrm{~mm}^{3}$ sample was placed in an aluminium titanate sample holder with a silicon carbide cap. The sample was located in the high temperature furnace chamber which was evacuated and back filled with argon. A sustained flow of $100 \mathrm{ml}$ per minute of argon cover gas was then fed through the chamber throughout the experiment. The temperature change of the sample was detected using an InSn IR detector cooled by liquid nitrogen. Temperature steps of $50{ }^{\circ} \mathrm{C}$ were taken from 50 to $1000{ }^{\circ} \mathrm{C}$. Five measurements were performed at each temperature step and the standard deviation calculated. The thermal diffusivity was calculated using the Cowon method with pulse correction applied [35]. This model takes into account heat loss from all surfaces of the sample. Correction for the duration of the laser impulse and its real shape were included in the calculation. The bulk density was measured using the method of hydrostatic weighing, employing Archimedes' principle [36].

A Netzsch powder crucible was used for the measurement of the powder 316L SS material. The crucible was filled with powder and tapped to allow the powder to settle. Once filled a sapphire lid was placed in contact with the powder and the crucible screwed shut. The crucible was then placed in the LFA and heated under an argon atmosphere and the diffusivity determined using the Cowen+ pulse correction model.

The method of hydrostatic weighing using Archimedes' principle was used to determine the density of the samples [36]. An attension tensiometer was used to determine the mass of the sample in air and in distilled water. From the mass change, the density can be calculated using the following relation:

$\rho_{s}=Z \frac{M}{\Delta M}$

where $\rho_{s}$ is the density sample, $Z$ is the water density, $M$ the initial sample mass and $\Delta M$ is the difference between mass in air and in water. It is noted that the density values for air and water were taken at $25^{\circ} \mathrm{C}$.

The tap density of the powder material was measured using the ASTM B527 - 15 [37] Standard Test Method for Tap Density of Metal Powders and Compounds and a Freeman FT4 powder Rheometer. The powder was placed into a $25-\mathrm{ml}$ container, tapped to settle and the mass of the powder measured.

\subsection{Specific heat capacity}

Using a Netzsch LFA 457 and employing the ratio method, the specific heat capacity $C_{p}$ of $316 \mathrm{~L}$ SS solid was calculated using a Pyroceram reference sample. The Netzsch Proteus software takes the infinite time extrapolated, heat loss corrected voltage, $\mathrm{V}$ of the detector signal corrected by the amplification factors and calculates $C_{p}$.
Table 1 Chemical composition percentage of mass for $316 \mathrm{~L}$ powder used in experiments as specified by the supplier

\begin{tabular}{llllllll}
\hline $\mathrm{C}$ & $\mathrm{Cr}$ & $\mathrm{Cu}$ & $\mathrm{Fe}$ & $\mathrm{Mn}$ & $\mathrm{Mo}$ & $\mathrm{Ni}$ & $\mathrm{Si}$ \\
\hline $0.03(\max )$ & $16.00-18.00$ & 0.3 & 65 & $2.00(\max )$ & $2.00-3.00$ & $10.00-14.00$ & $1.00(\max )$ \\
\hline
\end{tabular}


Fig. 6 SEM image of gas atomised $316 \mathrm{~L}$ stainless steel produced by Sandvik Osprey used for experiments

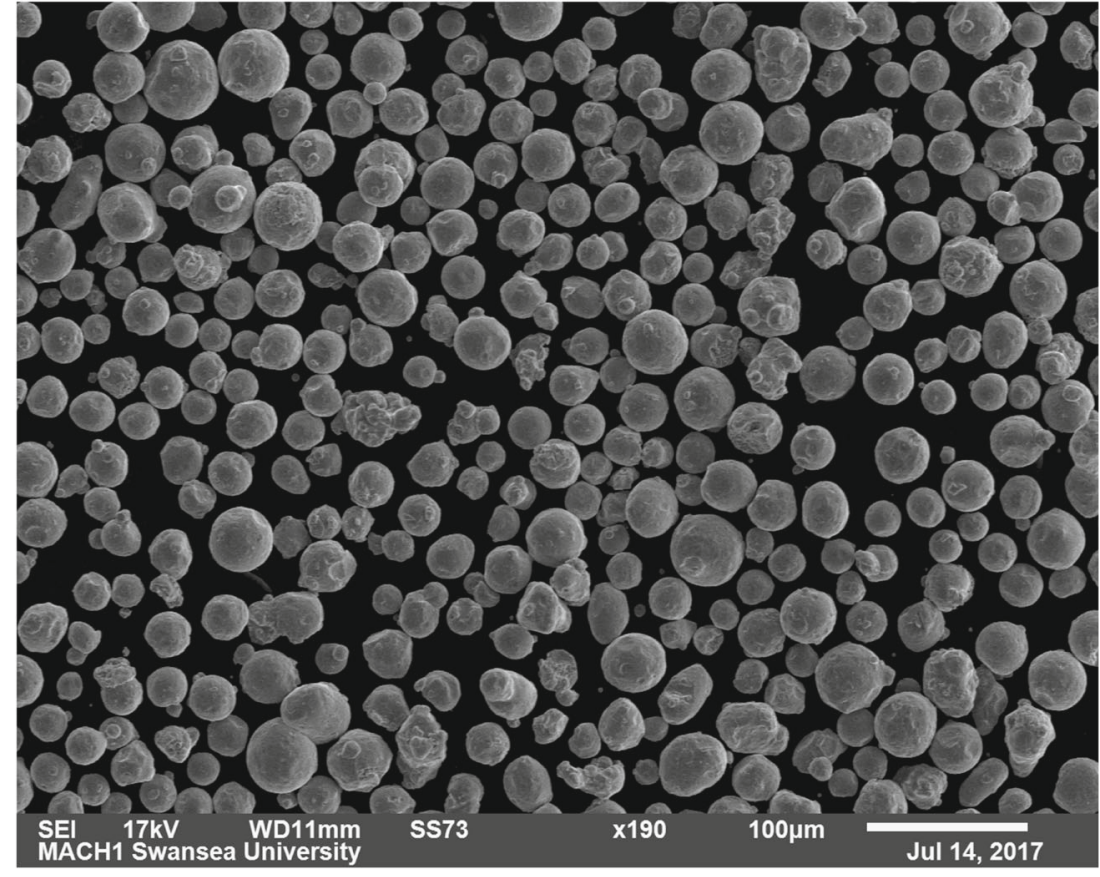

The specific heat capacity of the 316L SS powder was measured using a Differential Scanning Calorimeter (DSC) 404 F1 Pegasus High-Temperature DSC and was determined using the DIN 51007 method for thermal analysis [38], using a sapphire reference and alumina lined platinum crucibles under argon gas. The powder was measured using this technique because the $C_{p}$ could not be accurately determined using the LFA ratio method due the thermal diffusivity values being much lower than the values from the reference standards available. The accuracy of a $C_{p}$ measurement is vitally dependent on the reproducibility of the baseline measurement. Three measurements are necessary for the calculation of the specific heat: the base line, the sample and the reference standard (in this case sapphire). Within this series of measurements, the following test parameters must be identical, i.e. the atmosphere in the measuring cell, the flow rate for operation with dynamic gas, the initial temperature heating rate and scanning rate (sampling interval), the mass of crucible and lid and the position of crucible in the cell.

The thermal conductivities of the solid and powder materials can be calculated through the Laplace relation

$\kappa(T)=\alpha(T) \rho(T) C_{p}(T)$

Where $\mathrm{k}$ is the thermal conductivity $\left(W m^{-1} K^{-1}\right), \alpha$ the thermal diffusivity $\left(\mathrm{m}^{2} \mathrm{~s}^{-1}\right), \rho$ is the density $\left(\mathrm{kgm}^{-3}\right)$ and $C_{p}$ the specific heat capacity $\left(\mathrm{Jkg}^{-1} \mathrm{~K}^{-1}\right)$. Table 2 summarises the equipment used for measurement properties and Table 3 outlines the measured values for each property.

\section{Single line experiments}

A Renishaw AM400 laser powder bed fusion machine was used to perform single line experiments using a modulated $400 \mathrm{~W}$ ytterbium fibre laser with a $70 \mu \mathrm{m}$ beam width. A modulated laser deposits energy on a point-to-point basis for a specified period, the exposure time $e_{t}$, where the point distance $p_{d}$ is defined by the length between the centres of subsequent laser exposures. The effective line speed for a modulated laser can be calculated as $v=p_{d} / e_{t}$. A schematic showing the differences between a modulated laser and a continuous laser is shown in Fig. 7.

Gas atomized 316L SS powder from Sandvik Osprey was used for experiments of 60 single line welds. The powder was manually spread onto a $316 \mathrm{~L}$ stainless steel base plate $(200 \mathrm{~mm} \times 25 \mathrm{~mm} \times 1 \mathrm{~mm})$ to give a layer thickness of $50 \mathrm{\mu m}$. The base plate contained 5 milled cross-sections which could hold 5 individual 316L plates. A series of 3 $\mathrm{mm}$ long single line tracks were deposited with variation of power and exposure time under an argon atmosphere. Power increased linearly from $75 \mathrm{~W}$, in increments of $25 \mathrm{~W}$, to a maximum laser power of $200 \mathrm{~W}$. A series of exposure times were used for each set of laser powers ranging from $60 \mu \mathrm{s}$ to $600 \mu \mathrm{s}$ giving equivalent lines speeds of between $1 \mathrm{~m} / \mathrm{s}$ to $0.1 \mathrm{~m} / \mathrm{s}$ when using a point distance of $60 \mu \mathrm{m}$. The range of input parameters is shown in Table 4 and the experimental set up is shown in Fig. 8.

The substrate strips on which the single lines were deposited were cut prior to observation using a wire-electrical discharging machine (wire-EDM) between each test sample, between power values $125 \mathrm{~W}$ and $150 \mathrm{~W}$ and vertically through each 
Table 2 Equipment used for measured properties

\begin{tabular}{lllll}
\hline Property & Symbol & Units & Equipment & Equipment Temperature Range ${ }^{\circ} \mathrm{C}$ \\
\hline Thermal diffusivity & $\alpha$ & $\mathrm{m}^{2} \mathrm{~s}^{-1}$ & Netzsch LFA 457 (LFA) & RT-1600 \\
Coefficient of thermal expansion & $\beta$ & $\mathrm{K}^{-1}$ & Netzsch Dilatometer (DIL) & RT-1600 \\
Specific heat capacity & $C_{p}$ & $\mathrm{Jkg}^{-1} \mathrm{~K}^{-1}$ & Netzsch STA 449 (DSC) & RT-1100 \\
Thermal conductivity & $\kappa$ & $\mathrm{Wm}^{-1} \mathrm{k}^{-1}$ & LFA, DIL, DSC & RT-1100 \\
Tap density & $\rho_{t}$ & $\mathrm{kgm}^{-3}$ & & RT \\
\hline
\end{tabular}

Table 3 Measured temperature dependent thermophysical properties of $316 \mathrm{~L}$ stainless steel

\begin{tabular}{|c|c|c|c|c|c|c|c|c|c|}
\hline \multirow{2}{*}{$\begin{array}{l}\text { Temperature }{ }^{\circ} \mathrm{C} \\
\mathrm{T}(\mathrm{C})\end{array}$} & \multicolumn{3}{|c|}{ Thermal Conductivity $\left(\mathrm{Wm}^{-1} \mathrm{~K}^{-1}\right)$} & \multicolumn{3}{|c|}{ Specific Heat Capacity $\left(\mathrm{Jkg}^{-1} \mathrm{~K}^{-1}\right)$} & \multicolumn{3}{|c|}{ Density $\left(\mathrm{kgm}^{-3}\right)$} \\
\hline & Powder $k_{p}$ & Substrate $k_{s}$ & Solid [39] & Powder $C p_{p}$ & Solid $C p_{s}$ & Solid [39] & Powder $\rho_{p}$ & Solid $\rho_{s}$ & Solid [39] \\
\hline 50 & 0.013 & 16.64 & & 480 & 442 & & 4710 & 7929 & \\
\hline 100 & 0.029 & 17.35 & 15.5 & 483 & 472 & 490 & 4288 & 7991 & 7921 \\
\hline 150 & 0.092 & 17.9 & & 515 & 470 & & 4466 & 7988 & \\
\hline 200 & 0.147 & 18.45 & 17.6 & 535 & 483 & 520 & 4431 & 7990 & 7880 \\
\hline 250 & 0.119 & 18.95 & & 545 & 491 & & 4456 & 7985 & \\
\hline 300 & 0.13 & 19.47 & 19.4 & 553 & 499 & 540 & 4435 & 7994 & 7833 \\
\hline 350 & 0.123 & 20.17 & & 553 & 500 & & 4448 & 7988 & \\
\hline 400 & 0.123 & 21.44 & 21.8 & 550 & 524 & 560 & 4385 & 7985 & 7785 \\
\hline 450 & 0.141 & 21.97 & & 553 & 526 & & 4396 & 7989 & \\
\hline 500 & 0.127 & 22.91 & 23.4 & 552 & 537 & 570 & 4424 & 7990 & 7735 \\
\hline 550 & 0.128 & 24.14 & & 541 & 554 & & 4464 & 7996 & \\
\hline 600 & 0.074 & 24.93 & 24.5 & 536 & 560 & 590 & 4314 & 7983 & 7681 \\
\hline 650 & 0.105 & 27.97 & & 534 & 616 & & 4369 & 7987 & \\
\hline 700 & 0.118 & 28.97 & 25.1 & 535 & 627 & 600 & 4411 & 7994 & 7628 \\
\hline 750 & 0.121 & 36.09 & & 533 & 778 & & 4365 & 7985 & \\
\hline 800 & 0.125 & 42.34 & 27.2 & 534 & 939 & 630 & 4334 & 7991 & 7575 \\
\hline 900 & 0.095 & 44.21 & & 492 & 920 & & 4388 & 7991 & 7520 \\
\hline 1000 & 0.143 & 38.61 & 29.1 & 502 & 771 & 660 & 4316 & 7984 & 7462 \\
\hline $1389\left(t_{s}\right)$ & - & - & - & & & $710 *$ & - & - & 7269 \\
\hline $1413\left(t_{l}\right)$ & - & - & - & & & $720 *$ & - & - & 7236 \\
\hline
\end{tabular}

Fig. 7 Comparison of left; modulated laser and right; continuous laser
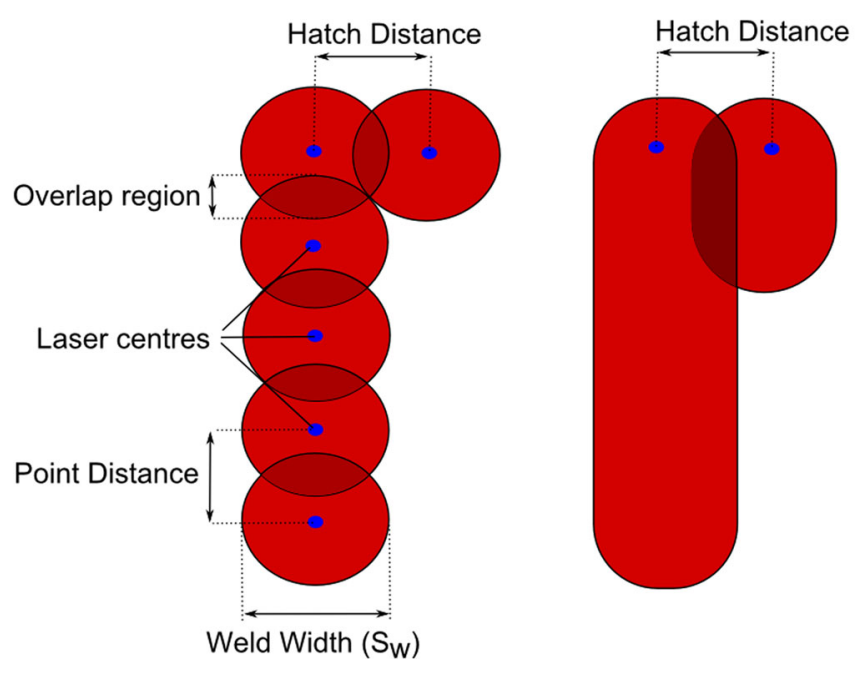

Laser direction moving at Scanning speed (v) 
Table 4 L-PBF deposition parameters of power and exposure time using a constant point distance of $60 \mu \mathrm{m}$ and beam diameter of $70 \mu \mathrm{m}$

\begin{tabular}{lllllll}
\hline Laser power W: & 75 & 100 & 125 & 150 & 175 & 200 \\
\hline Line speed (m/s) & 1.0 & 1.0 & 1.0 & 1.0 & 1.0 & 1.0 \\
& 0.9 & 0.9 & 0.9 & 0.9 & 0.9 & 0.9 \\
& 0.8 & 0.8 & 0.8 & 0.8 & 0.8 & 0.8 \\
& 0.7 & 0.7 & 0.7 & 0.7 & 0.7 & 0.7 \\
& 0.6 & 0.6 & 0.6 & 0.6 & 0.6 & 0.6 \\
& 0.5 & 0.5 & 0.5 & 0.5 & 0.5 & 0.5 \\
& 0.4 & 0.4 & 0.4 & 0.4 & 0.4 & 0.4 \\
& 0.3 & 0.3 & 0.3 & 0.3 & 0.3 & 0.3 \\
& 0.2 & 0.2 & 0.2 & 0.2 & 0.2 & 0.2 \\
& 0.1 & 0.1 & 0.1 & 0.1 & 0.1 & 0.1 \\
\hline
\end{tabular}

set of single lines. Each sample was then hot compression mounted in high edge retention resin for cross sectional analysis. The samples were ground using a diamond disk until the surface was planar and then polished using oil based diamond solution ranging from 9-1 $\mu \mathrm{m}$. The cross sections were then etched using a $100 \mathrm{ml}$ ethanol, $100 \mathrm{ml}$ $\mathrm{HCI}, 5 \mathrm{~g} \mathrm{CuCl} 2$ solution to distinguish the microstructure and differentiate between weld and substrate. A Zeiss Smartzoom 5 optical microscope was used to measure the height, width and depth of each single line weld as shown in Fig. 9.

\subsection{Track morphology}

Figure 10 gives an overview of the track morphology. Each column represents a single example from three repeat experiments (Test 1, Test 2 and Test 3) while the rows indicate laser power. Each subsection row is labelled 1-10 decreasing effective line speed with reference to Table 4.

Some tracks have insufficient power and exposure time to melt the powder (e.g. $75 \mathrm{~W}$ lines 1-3). Other tracks have melted powder but are not continuous between successive welds due to the balling effect (e.g. 125W lines 4-5). Some tracks are continuous but irregular (e.g. 175W lines 7-8). Others are continuous and regular (e.g. 200W lines 9-10).

In the L-PBF process, continuous and regular tracks are desirable. Departure from continuous regular tracks can lead to part failure or unwanted localised porosity. It is therefore important to identify the correct operating input parameters to minimise the chances of failures or localised porosity. An illustration of whether a track morphology is continuous, irregular or balled is also shown in Fig. 9b.
Fig. 8 Schematic of single line experiments set up

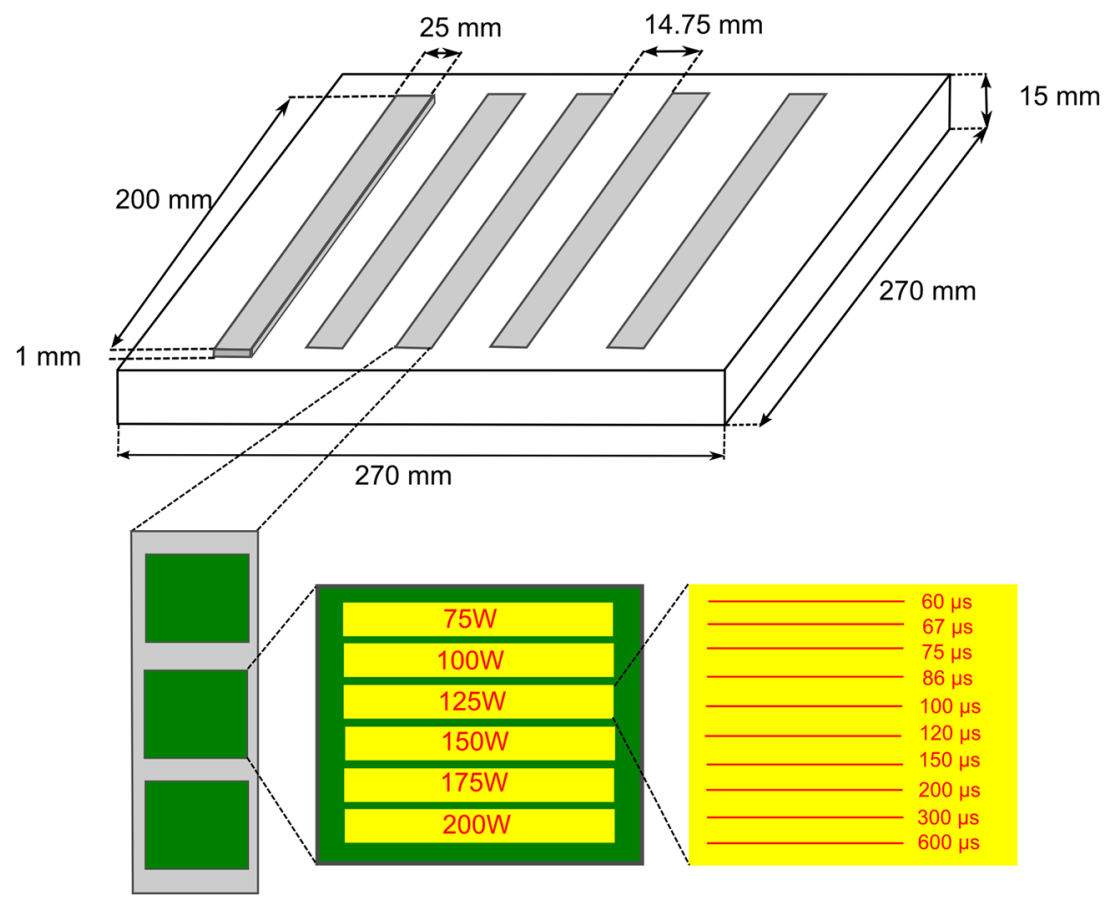


Fig. 9 Examples of left; balling $125 \mathrm{~W} 0.8 \mathrm{~m} / \mathrm{s}$ middle; conduction weld $100 \mathrm{~W} 0.1 \mathrm{~m} / \mathrm{s}$ and right; keyhole weld $200 \mathrm{~W}$ $0.1 \mathrm{~m} / \mathrm{s}$. Track height, width and depth measurements are outlined

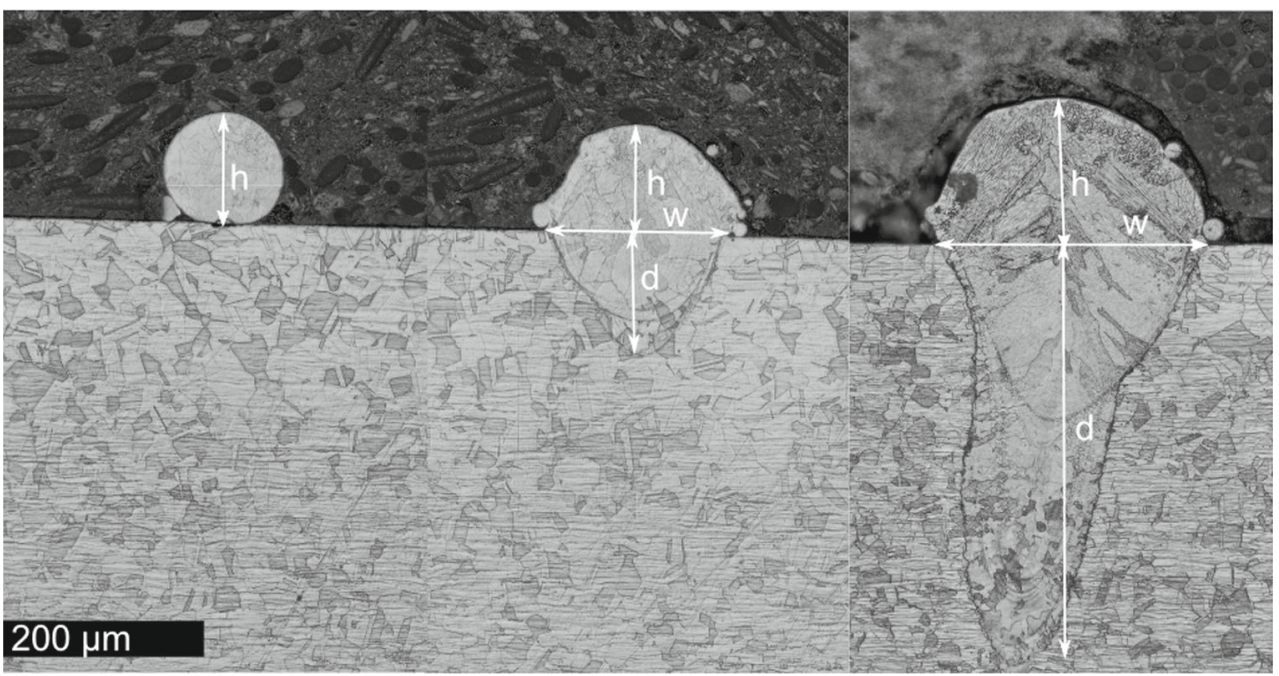

\subsection{Cross-sectional profiles}

The cross-sectional height and width of the track varied depending on the type of track morphology, as shown in Fig. 10. When considering cross sections, the weld is defined by the visualised consolidated solidified region of material. The weld width is defined by the distance of the weld along the level of the substrate, the height is taken from the top of the weld to the level of the substrate and the depth is taken from the substrate to the bottom of the weld.

All track profiles are shown as a 'process map' in Fig. 11. Tracks which have balled or are irregular will have larger variations in height and width profiles. This means the measurements will be dependent on the chosen cross section, which is difficult to accurately control using grinding methods. However, for continuous track morphologies heights and widths are more consistent which is reflected in the measured data. To account for this the grinding, polishing and measurements of samples were undertaken three times for each of the three repeat experiments, each measured at different locations giving nine readings in total for each weld profile.

\subsection{Cross-sectional dimensional analysis}

Figure 12 shows the width, depth and height measurements, respectively for three repeat experiments with three cross sectional readings with variation bars of $+/$ - one standard deviation.

The weld widths show an increase as line speed decreases and power increases. At higher line speeds, for all powers, it can be observed that there is a larger variation due to the lack of continuity in the welded lines as explained above.
For $75 \mathrm{~W}$ depositions, out of ten line speeds only the slowest three line speeds create a weld attached to the substrate. As the power increases and the line speed decreases this causes a much wider weld with greater depth and as the lines are generally more continuous this leads to smaller variation in the measurements.

The depth measurements follow a similar trend to that of the widths. As the power increases and the line speed decreases does the heat penetration into the substrate. At lower power and faster line speeds there is not enough energy to penetrate through the powder layer leading to a lack of consolidation between the welded line and the underlying substrate. It is believed that the primary reason for this lack of melting is due to the high reflectivity of powder and its low conductivity. At high powers and slow line speeds the depth of the penetration can rise to around nine times that of the powder layer thickness. Such deep welds are associated with the keyhole mode of melting which is caused by the vapour recoil pressure which creates a deep surface depression of the melt pool. The laser light then interacts with the steep melt pool walls and with the ejected vapours, where a larger amount of the laser's energy is absorbed in comparison to the conduction mode of melting. This has been demonstrated by Trapp et al. [40] where they show that the absorptivity of the material increases once a keyhole is formed.

The height measurements display a vaguely similar trend to the weld widths and depths, although these are not used for modelling purposes due to limitations of the model. However, the errors margins are much larger in comparison for these measurements. It might be argued that there is a slight weld height increase with increasing power and decreasing line speed but with such large variations in measurement this is not conclusive. 
Fig. 10 a Confocal images of single line tracks varying power and exposure time. Layer thickness $(50 \mu \mathrm{m})$ and laser spot size $(70 \mu \mathrm{m})$ were kept constant throughout the experiment. b Categorisation of track morphologies (1) balling, (2) irregular and (3) continuous

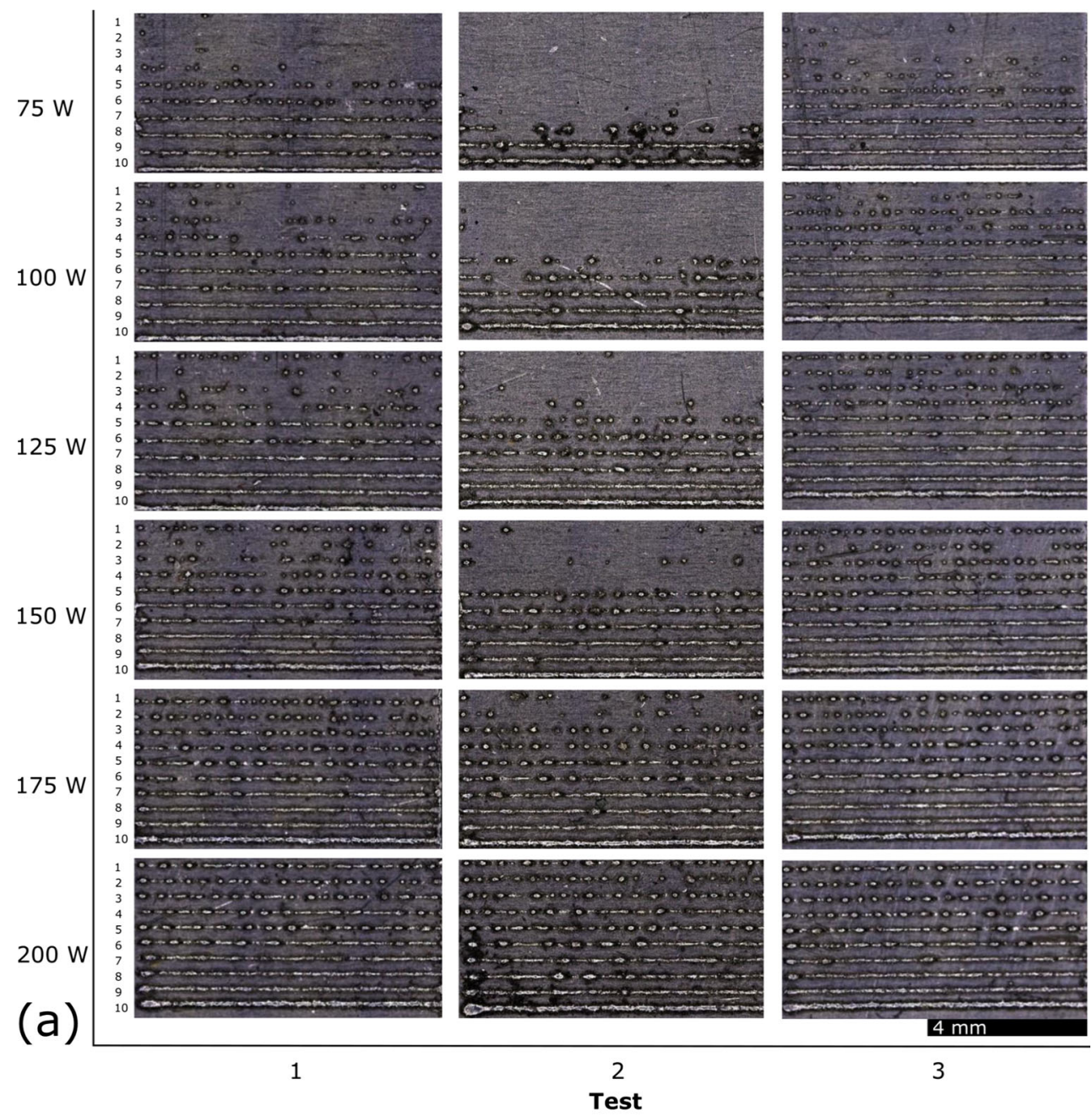

1. $200 \mathrm{w}, 0.9 \mathrm{~m} / \mathrm{s}$

2. $200 \mathrm{~W}, 0.5 \mathrm{~m} / \mathrm{s}$ 3. $200 \mathrm{w}, 0.1 \mathrm{~m} / \mathrm{s}$

(b)

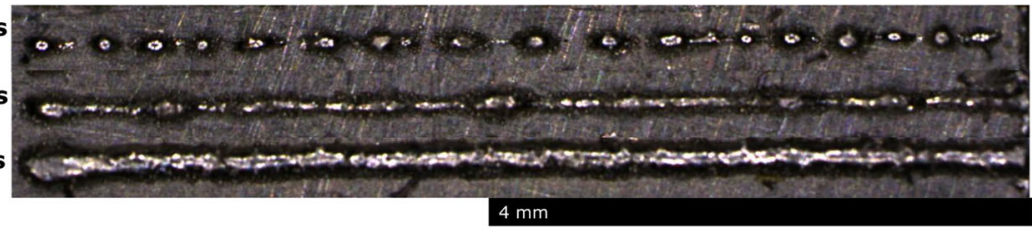

\section{Model analysis and simulations}

\subsection{Weld dimensions}

A new pragmatic modelling approach for prediction of keyhole mode welds has been presented. In this section, a comparison to the experimental widths and depths, and weld mode prediction is presented shown in Figs. 13 and 14 , respectively. In addition, the weld depth penetration prediction is compared to an analytical solution as derived in
[33], in which the relationship between depth of penetration to the laser powder and scanning speed is described by:

$d=\frac{A P}{2 \pi k T_{b}} \ln \left(\frac{\sigma+\frac{D}{v}}{\sigma}\right)$

where $d$ is the penetration depth $(m), A$ is the material absorptivity (dimensionless), $P$ is the laser power $(W), k$ is the thermal conductivity $\left(\mathrm{Wm}^{-1} \mathrm{~K}^{-1}\right), T_{b}$ is the boiling point of the material $(K), \sigma$ is the spot size of the laser 
Fig. 11 Process map of cross sections as a function of laser power $(\mathrm{W})$ and effective line speed $(\mathrm{m} / \mathrm{s})$

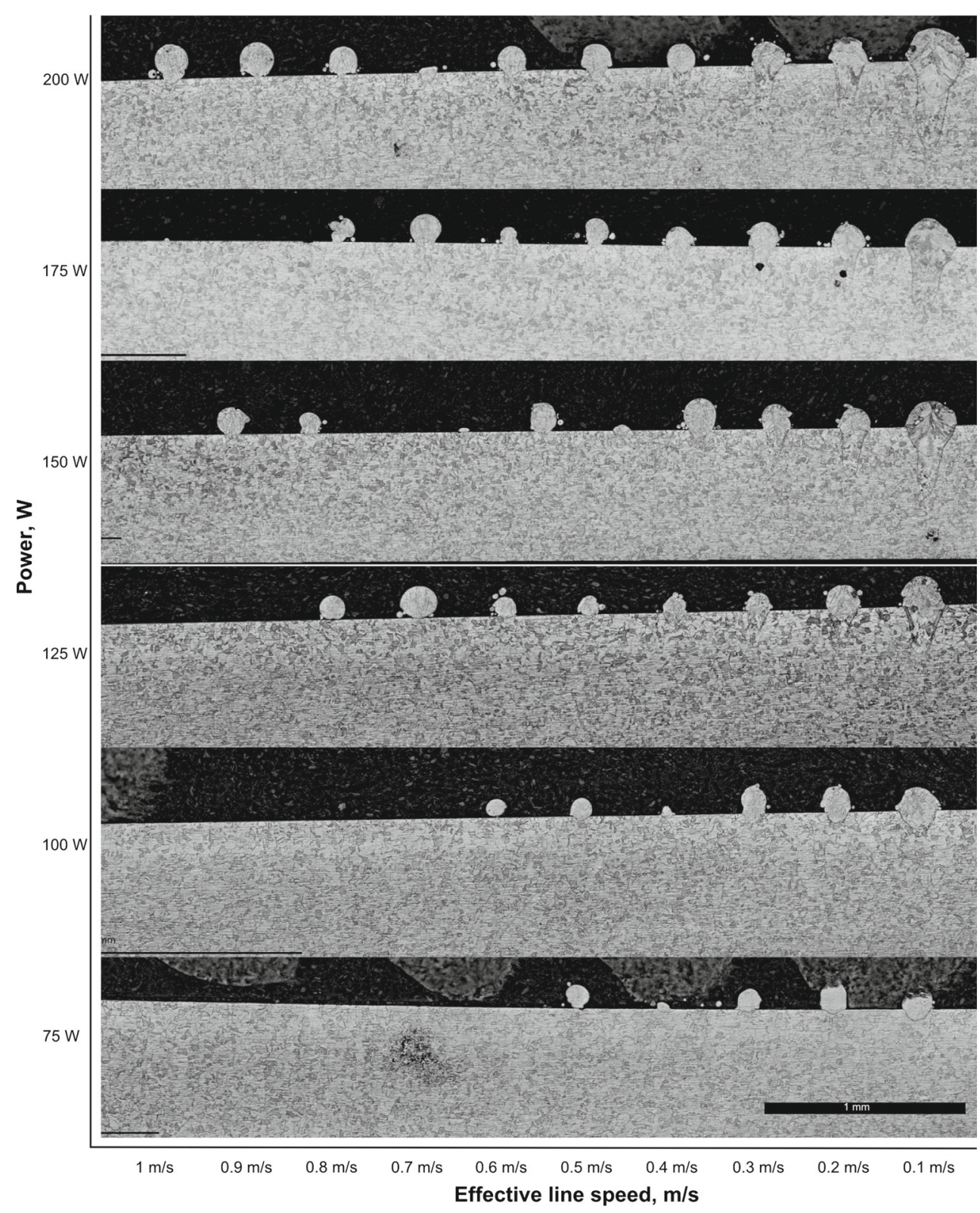

beam $(m)$ and $v$ is the scanning speed $(m / s)$. All the material properties for this calculation are the same as used in previous numerical modelling.

The same input parameters as experiments were distributed on a HPC cluster resulting in the 60 deposition parameters being solved in approximately 4 hours. Comparing weld width and depth in Fig. 13 it can be observed that the model follows the trends for width and depth well.

For weld width prediction for lower powers and faster line speeds (e.g. $100 \mathrm{~W} 1.0-0.5 \mathrm{~m} / \mathrm{s}$ ) the model does not predict penetration into the substrate hence zero weld width. Also, for the slowest lines speeds the model under predicts the weld width. It is believed that in these regions thermofluidic effects will be dominant which is not captured in the model. However, for the vast range of parameters (e.g. 175 W $1.0-0.1 \mathrm{~m} / \mathrm{s}$ ) the model predicts the weld width with good accuracy and clearly follows the observed trends.

When comparing the depths, the model slightly under predicts these. However, simulations are very close to experimental variation and clearly follow the same trend as experiments. There is a marked improvement in weld depth prediction against the analytical solution further supporting the usefulness of the model. These results demonstrate that using an appropriate model for material ablation and 

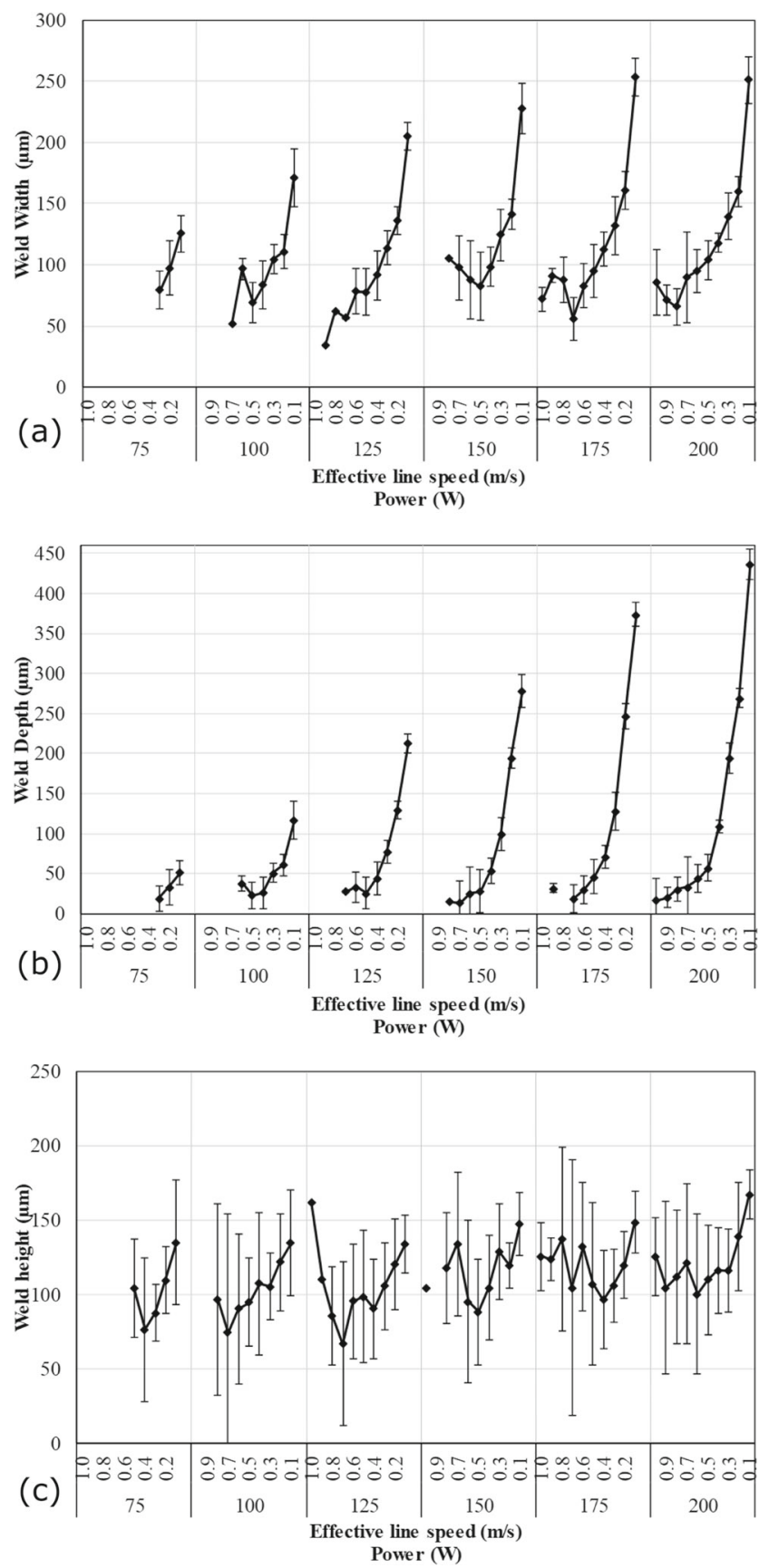

Fig. 12 a Weld widths, $\mathbf{b}$ depths and $\mathbf{c}$ heights as a function of laser power and exposure time. Constant layer thickness of $50 \mu \mathrm{m}$, point distance of $60 \mu \mathrm{m}$ and laser beam width of $70 \mu \mathrm{m}$

appropriate energy absorption, without a fluidic model, good trends for weld widths and depths can be achieved. The model could potentially be strengthened by using an appropriate thermofluidic solver but the increased computational expense coupled with an appropriate powder spreading model may reduce practical applicability of the model which might not justify the slight increase in accuracy.

\subsection{Melting mode}

The laser input parameters can be combined into a normalised enthalpy and correlated against the depth normalised by the beam size, as done by King et al. [41] based on previous work carried out on laser welds by Hann et al. [42]. The normalised enthalpy combines the effects of power, speed and beam size and is given by:

$\frac{\Delta H}{h_{s}}=\frac{A P}{h_{s} \sqrt{\pi D v \sigma^{3}}}$

where $A$ is the absorptivity of the material, $P$ the laser power $(W), h_{s}=\rho c T_{m}$ enthalpy at melting $\left(\mathrm{Jkg}^{-1}\right)$ and $D$ the diffusivity $\left(m^{2} s^{-1}\right)$. A keyhole weld is defined when the depth to half width ratio is greater than 1.5. The model is then compared with the experiments and shown in Fig. 14 for weld mode prediction.

When comparing the prediction of weld mode in Fig. 14, the model predicts the transition in weld modes within $13 \%$ of experiments and follows the trend of this transition in the conduction and keyhole mode. Analysing the experimental results, the transition from conduction to keyhole mode is
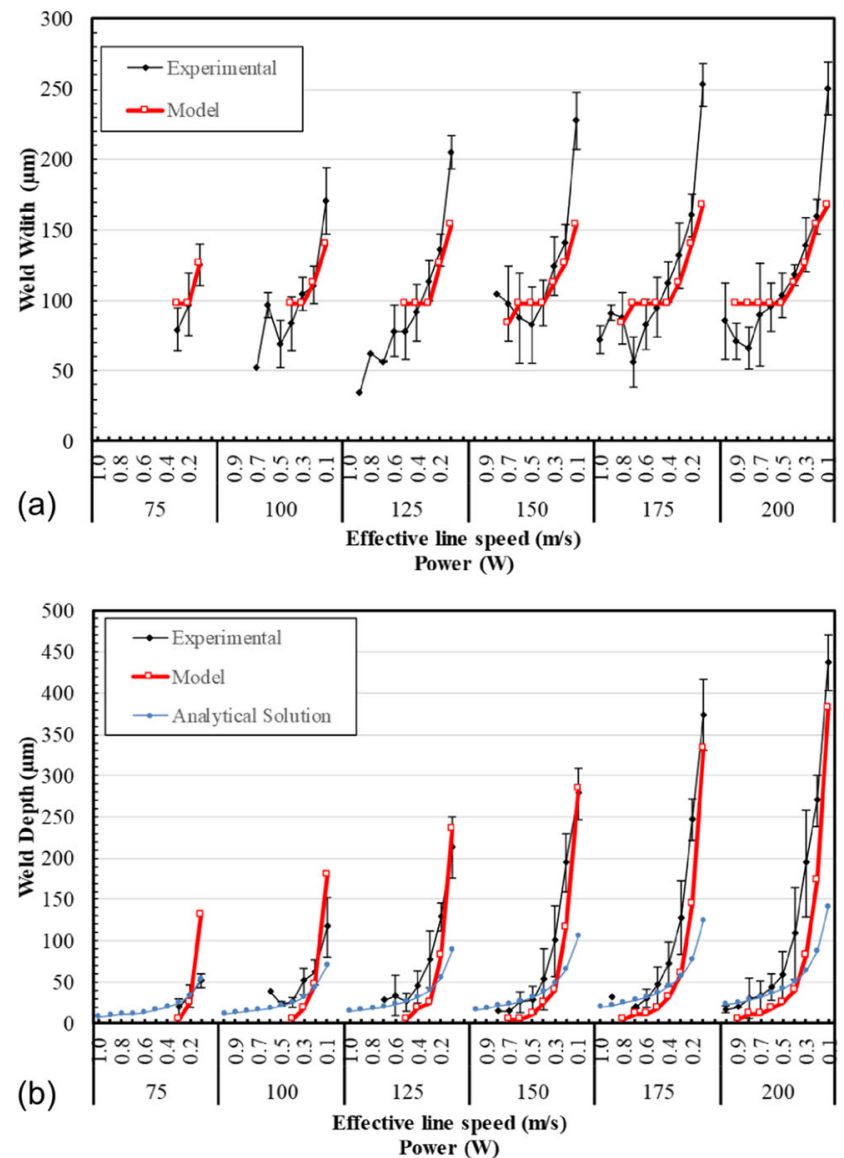

Fig. 13 a Weld widths, $\mathbf{b}$ weld depths, experimental and simulation as a function of laser power and line speed. Constant layer thickness of $50 \mu \mathrm{m}$, point distance of $60 \mu \mathrm{m}$ and laser beam width of $70 \mu \mathrm{m}$ 

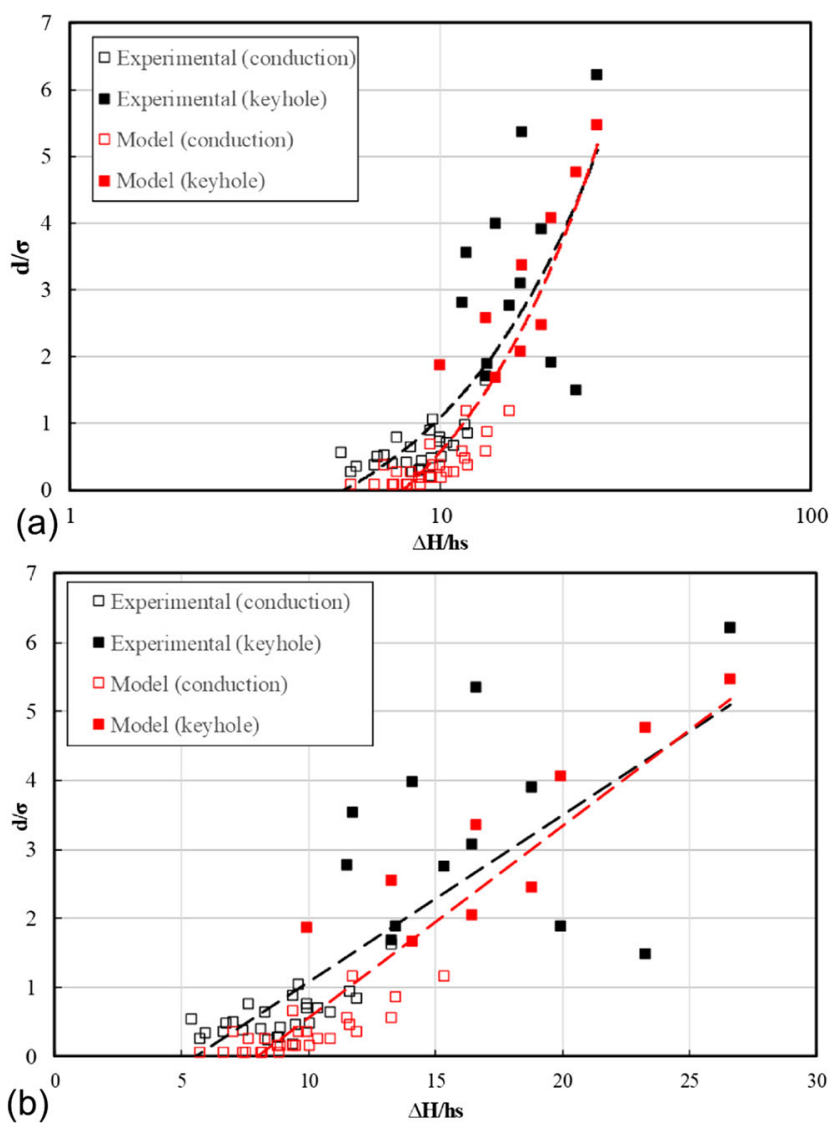

Fig. 14 Melt pool depth normalised by beam size as a function of normalised enthalpy for experimental results and model 1. a Linear and b semi-log scale. Linear curves are fitted to data points, experimental (black) and model (red)

seen to occur at a normalised enthalpy value of $\sim 11$. In experiments by King et al. [41], this transition is observed at a normalised enthalpy value of $\sim 30$ and Bertoli et al. [43] observe this transition at $\sim 6$. The theoretical threshold value for the weld mode transition can be estimated as the following according to [41]

$\frac{\Delta H}{h_{s}}>\frac{\pi T_{b}}{T_{m}} \approx 6$

These differences in transition thresholds between conduction to keyhole mode might be explained by subtle differences in experimental set up, particularly relatively small differences in beam size, powder bed depths, powder size distributions and laser modulation.

The following simulations were run varying powder layer thicknesses and beam widths using the same range of normalised enthalpy values. The layer thickness was varied from 30 to $200 \mu \mathrm{m}$ and the results are shown in Fig. 15 and the beam width is varied from 70 to $210 \mu \mathrm{m}$ shown in Fig. 16.
Figure 15 shows that a smaller layer thickness will experience a larger amount of keyhole welds over the range of simulated deposition parameters and these also undergo a weld mode transition at a lower normalised enthalpy value $\sim 10$. As the layer thickness increases the value of $\Delta H / h_{s}$ for transition to a keyhole weld increases. $\Delta H / h_{s}$ for 50 $\mu \mathrm{m}$ is $\sim 10$, for $75 \mu \mathrm{m}$ is $\sim 13$ and for $100 \mu \mathrm{m}$ is $\sim 17$. For a $200 \mu \mathrm{m}$ layer thickness no keyhole welds would be experienced but only 3 welds formed from the total of 60 variations in deposition parameters used.

As the beam width increases, this causes the energy intensity of the laser beam to reduce as it is distributed through the larger projected area of the laser beam. This is reflected in simulation results, where generally wider and shallower welds are formed. Figure 16 outlines the effect of beam width on the normalised depth as a function of normalised enthalpy.

Due to this increase in weld width and decrease in depth (as the beam width is increased) the weld mode changes as a function of the beam width. As the beam width increases the value of $\Delta H / h_{s}$ for transition to a keyhole weld increases.
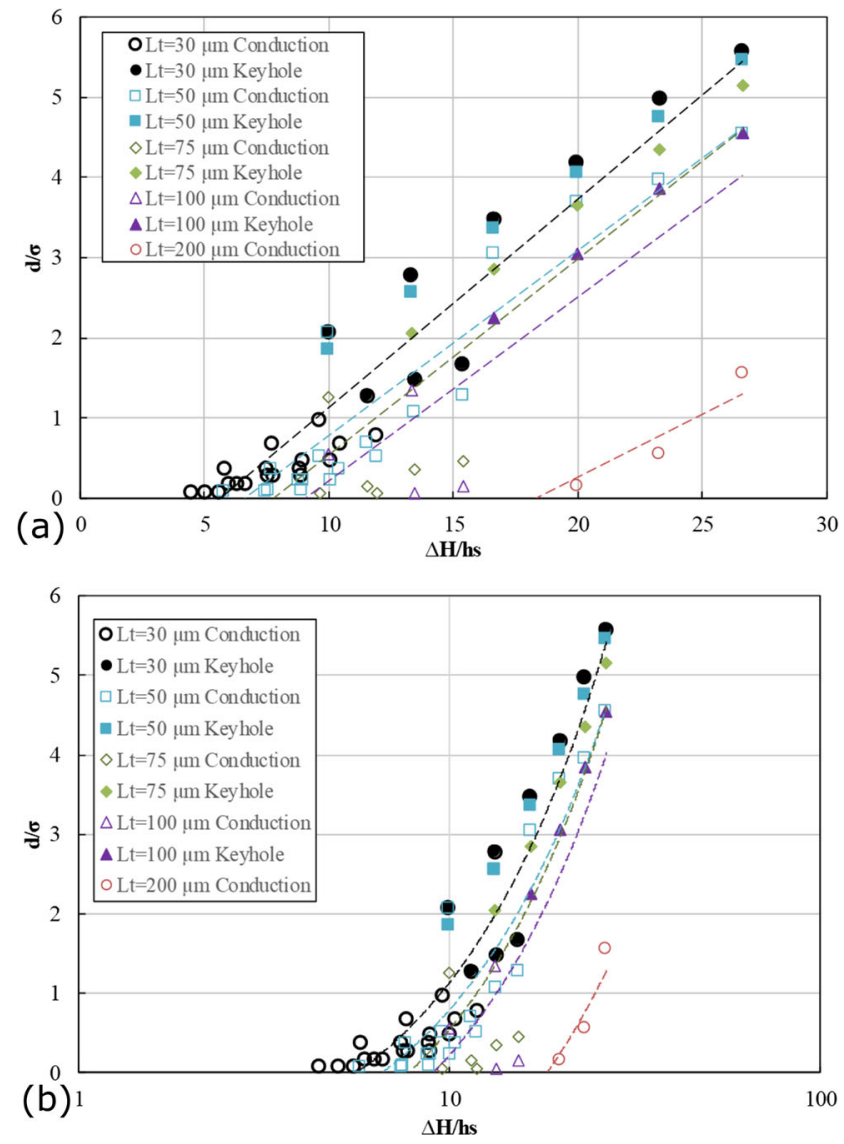

Fig. 15 Model results varying layer thicknesses showing melt pool depth normalized by beam size as a function of normalized enthalpy. top) linear and bottom) semi-log scale. Linear curves are fitted to data points 

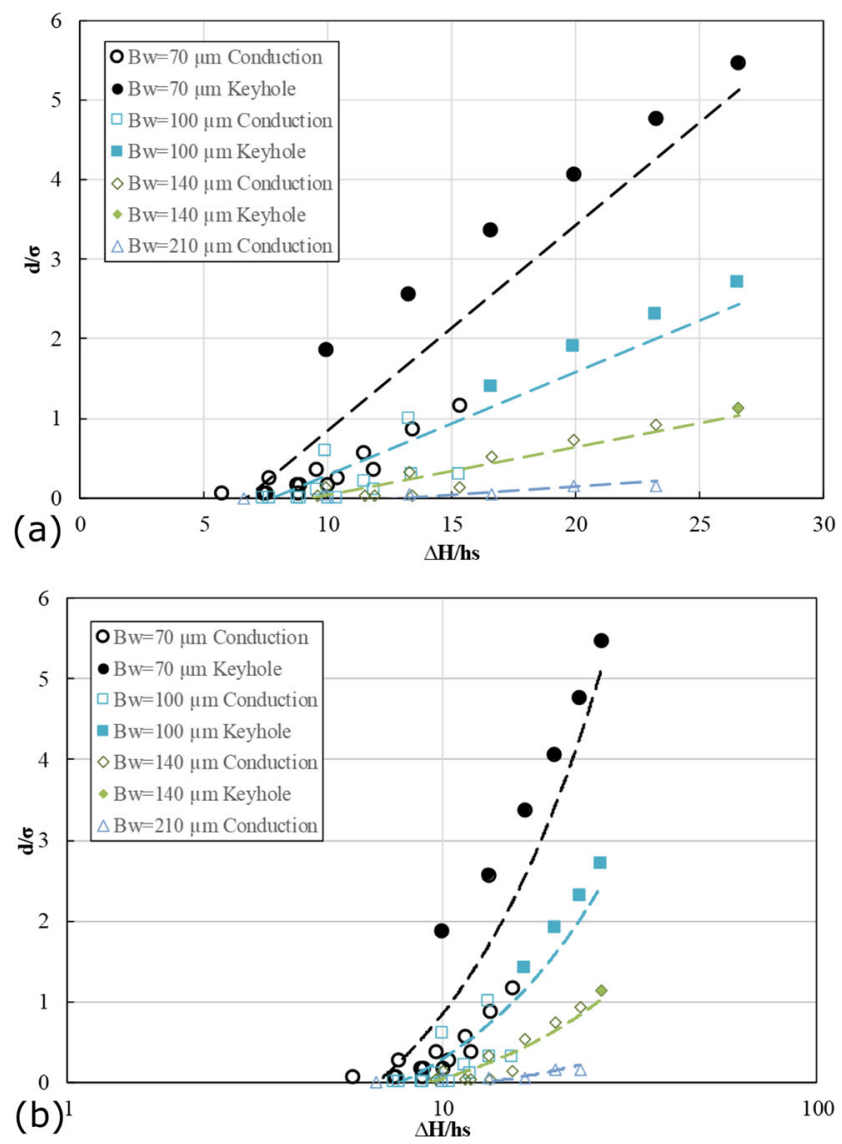

Fig. 16 Model results varying beam widths showing melt pool depth normalized by beam size as a function of normalized enthalpy. a Linear and $\mathbf{b}$ semi-log scale. Linear curves are fitted to data points

The $\Delta H / h_{s}$ for $70 \mu m$ is $\sim 10$, for $100 \mu m$ is $\sim 17$ and for $140 \mu \mathrm{m} \sim 27$. For a $210 \mu \mathrm{m}$ beam width no keyhole mode welds are predicted.

\subsection{Weld profile}

In addition, a comparison of the weld profile from the model against the experiments shown in Fig. 17.

In Fig. 17, the predicted weld profile is similar to that of experiments. The model accurately captures the weld profile between the powder and the substrate due to the much larger differences in thermal conductivity between the powder and solid materials. The weld width is thicker at the boundary between powder and substrate due to the much larger conductivity of the solid material which is also captured in experimental results. The profile of the penetration into the substrate is very similar. However, the region in the weld within the substrate that transitions from conduction to keyhole, where a much steeper gradient is shown, is not captured in its entirety within the model as the effects causing this transition are largely fluidic which is not considered within the model.

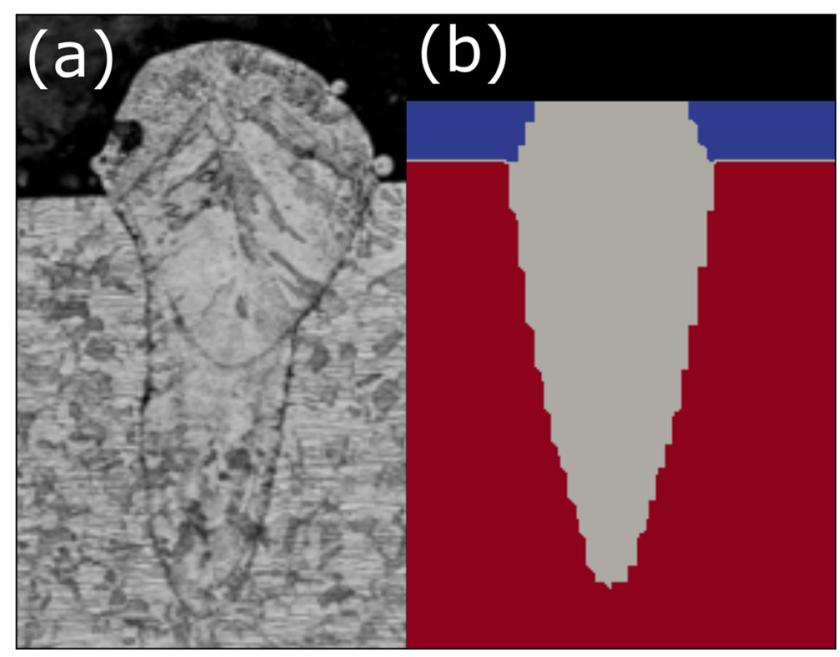

Fig. 17 Comparison of $\mathbf{a}$ experimental and $\mathbf{b}$ computational model cross sections for deposition parameters of $200 \mathrm{~W}$ and $0.1 \mathrm{~m} / \mathrm{s}$

\section{Conclusions}

In this paper, a pragmatic continuum level modelling approach for the prediction of keyhole mode welds has been presented and compared against single line experiments over 60 deposition parameters.

- A pragmatic continuum level model which includes an ablation limiting technique, measured thermophysical properties for powder and solid materials and a laser depth penetration approach has been presented to simulate single lines welds in the L-PBF process.

- Single line experiments of $316 \mathrm{~L}$ using a modulated laser have been presented over a range of deposition parameters indicating conditions required to transition from conduction to keyhole modes. The transition from conduction to keyhole mode regimes was found to occur at normalised enthalpies of 11 based on the experimental parameters chosen in this work. This is close to the theoretical transition and within the ranges of previous experimental work.

- Using the presented model, the predicted weld dimensions (width and depth) followed the same trends of experimental results and are largely improved over an analytical solution. In addition, the model can predict the onset of keyhole welds within $13 \%$ of experiments. These results reinforce the idea that lower fidelity models can predict the onset of keyhole mode welds with confidence.

- The simulations suggest that the powder layer thickness and beam width strongly contribute to the threshold value of normalised enthalpy marking the transition to keyhole mode melting. To this extent, the experimental 
control of the powder layer thickness may be a contributing factor to differences reported in previous work.

This modelling approach used here coupled with as measured thermo-physical properties allows for a continuum level approach for weld pool predictions without recourse to computationally expensive fluidic effects. This permits rapid predictions of optimal processing parameters for LPBF. This approach could be used as an ingredient in more accurate weld predictions for future multiscale modelling of the L-PBF process.

Acknowledgements The authors would like to thank the Welsh Government A4B funded Centre for Advanced Materials Characterisation (MACH1) and Advanced Sustainable Manufacturing Technologies (ASTUTE 2020) and EPSRC funded Centre for Innovative Manufacturing in Laser-based production Processes (EP/K030884/1) for the Innovation Project which allowed some of the preliminary development of the WELD-AM models, as well as Professor Stewart Williams and Dr Wojciech Suder from Cranfield University for their helpful insights.

Funding information This study received funding from the Additive Manufacturing Products Division at Renishaw Plc., the Engineering and Physical Sciences Research Council (ESPRC), funded Engineering Doctoral Training (EDT), Manufacturing Advances Through Training Engineering Researchers (MATTER) scheme, the Welsh European Funding Office (WEFO), the Materials and Manufacturing Academy (M2A) and the European Social Fund through the Welsh European Funding Office.

Open Access This article is distributed under the terms of the Creative Commons Attribution 4.0 International License (http:// creativecommons.org/licenses/by/4.0/), which permits unrestricted use, distribution, and reproduction in any medium, provided you give appropriate credit to the original author(s) and the source, provide a link to the Creative Commons license, and indicate if changes were made.

Publisher's Note Springer Nature remains neutral with regard to jurisdictional claims in published maps and institutional affiliations.

\section{References}

1. Wang X, Gong X, Chou K (2017) Review on powderbed laser additive manufacturing of Inconel 718 parts. Proc Inst Mech Eng Part B J EngManuf 231(11):1890-1903. https://doi.org/10.1177/0954405415619883

2. Bourell DL (2016) Perspectives on additive manufacturing. Annu Rev Mater Res 46(1):1-18. https://doi.org/10.1146/annurevmatsci-070115-031606

3. Gao W, Zhang Y, Ramanujan D, Ramani K, Chen Y, Williams CB, Wang CC, Shin YC, Zhang S, Zavattieri PD (2015) The status, challenges, and future of additive manufacturing in engineering. Comput Des 69:65-89. https://doi.org/10.1016/j.cad.2015.04.001

4. Mindt HW, Megahed M, Lavery NP, Holmes MA, Brown SGR (2016) Powder bed layer characteristics: the overseen first-order process input. Metall Mater Trans A Phys Metall Mater Sci 47(8):1-12. https://doi.org/10.1007/s11661-016-3470-2
5. Cherry JA, Davies HM, Mehmood S, Lavery NP, Brown SGR, Sienz J (2014) Investigation into the effect of process parameters on microstructural and physical properties of 316L stainless steel parts by selective laser melting. Int J Adv Manuf Technol 76(58):869-879. https://doi.org/10.1007/s00170-014-6297-2

6. Sillars SA, Sutcliffe CJ, Philo AM, Brown SG, Sienz J, Lavery NP (2018) The three-prong method: a novel assessment of residual stress in laser powder bed fusion. Virtual Phys Prototyp 13(1):20 25. https://doi.org/10.1080/17452759.2017.1392682

7. Lavery NP, Cherry J, Mehmood S, Davies H, Girling B, Sackett E, Brown SG (2016) Sienz J (2017) Effects of hot isostatic pressing on the elastic modulus and tensile properties of $316 \mathrm{~L}$ parts made by powder bed laser fusion. Mater Sci Eng A 693:186-213. https://doi.org/10.1016/j.msea.2017.03.100

8. Körner C, Bauereiß A, Attar E (2013) Fundamental consolidation mechanisms during selective beam melting of powders. Model Simul Mater Sci Eng 21(8):085011. https://doi.org/10.1088/09650393/21/8/085011

9. Körner C, Attar E, Heinl P (2011) Mesoscopic simulation of selective beam melting processes. J Mater Process Technol 211(6):978987. https://doi.org/10.1016/j.jmatprotec.2010.12.016

10. Contuzzi N, Campanelli SL, Ludovico AD (2011) 3D finite element analysis in the Selective Laser Melting process. Int J Simul Model 10(3):113-121. https://doi.org/10.2507/IJSIMM10(3)1. 169

11. Fu CH, Guo YB (2014) Three-Dimensional Temperature gradient mechanism in selective laser melting of Ti-6Al-4V. J Manuf Sci Eng 136(6):061004. https://doi.org/10.1115/1.4028539

12. Gusarov AV, Smurov I (2010) Radiation transfer in metallic powder beds used in laser processing. J Quant Spectrosc Radiat Transf 111(17-18):2517-2527. https://doi.org/10.1016/j.jqsrt.2010.07. 009

13. Wits WW, Bruins R, Terpstra L, Huls RA, Geijselaers HJM (2016) Single scan vector prediction in selective laser melting. Addit Manuf 9:1-6. https://doi.org/10.1016/j.addma.2015.12.001

14. Boley CD, Khairallah SA, Rubenchik AM (2015) Calculation of laser absorption by metal powders in additive manufacturing. Appl Opt 54(9):2477-82. https://doi.org/10.1364/AO.54.002477

15. Khairallah SA, Anderson AT, Rubenchik A, King WE (2016) Laser powder-bed fusion additive manufacturing: Physics of complex melt flow and formation mechanisms of pores, spatter, and denudation zones. Acta Mater 108:36-45. https://doi.org/10.1016/ j.actamat.2016.02.014

16. Wits W, Becker JJ (2015) Laser beam welding of titanium additive manufactured parts. Procedia CIRP 28:70-75. https://doi.org/10.1016/j.procir.2015.04.013

17. Yadroitsev I, Gusarov A, Yadroitsava I, Smurov I (2010) Single track formation in selective laser melting of metal powders. J Mater Process Technol 210(12):1624-1631. https://doi.org/10.1016/j.jmatprotec.2010.05.010

18. Tolochko NK, Mozzharov SE, Yadroitsev IA, Laoui T, Froyen L, Titov VI, Ignatiev MB (2004) Balling processes during selective laser treatment of powders. Rapid Prototyp J 10(2):7887. https://doi.org/10.1108/13552540410526953

19. Yadroitsev I, Smurov I (2010) Selective laser melting technology: From the single laser melted track stability to 3D parts of complex shape. Phys Procedia 5(PART 2):551-560. https://doi.org/10.1016/j.phpro.2010.08.083

20. Fabbro R (2010) Melt pool and keyhole behaviour analysis for deep penetration laser welding. J Phys D Appl Phys 43(44):445501. https://doi.org/10.1088/0022-3727/43/44/445501

21. Fabbro R, Slimani S, Doudet I, Coste F, Briand F (2006) Experimental study of the dynamical coupling between the induced vapour plume and the melt pool for $\mathrm{Nd}-$ Yag $\mathrm{CW}$ laser welding. J Phys D Appl Phys 39(2):394-400. https://doi.org/10.1088/00223727/39/2/023 
22. Assuncao E, Williams S, Yapp D (2012) Interaction time and beam diameter effects on the conduction mode limit. Opt Lasers Eng 50(6):823-828. https://doi.org/10.1016/j.optlaseng.2012.02.001

23. Kumar N, Dash S, Tyagi AK, Raj B (2011) Melt pool vorticity in deep penetration laser material welding. Sadhana - Acad Proc Eng Sci 36(2):251-265. https://doi.org/10.1007/s12046-011-0017-5

24. Zhang Y, Li L, Zhang G (2005) Spectroscopic measurements of plasma inside the keyhole in deep penetration laser welding. $\mathrm{J}$ Phys D Appl Phys 38(5):703-710. https://doi.org/10.1088/00223727/38/5/007

25. Aalderink BJ, Lange DFD, Aarts RGKM, Meijer J (2007) Keyhole shapes during laser welding of thin metal sheets. J Phys D Appl Phys 40(17):5388-5393. https://doi.org/10.1088/0022-3727/40/ $17 / 057$

26. Sundar M, Nath aK, Bandyopadhyay D, Chaudhuri S, Dey P, Misra D (2007) Numerical simulation of melting and solidification in laser welding of mild steel. Int J Comput Mater Sci Surf Eng 1(6):717. https://doi.org/10.1504/IJCMSSE.2007.017926

27. Otto A, Schmidt M (2010) Towards a universal numerical simulation model for laser material processing. Physics Procedia 5(November):35-46. https://doi.org/10.1016/j.phpro.2010.08.120

28. Mościcki T, Hoffman J, Szymański Z (2006) Modelling of plasma plume induced during laser welding. J Phys D Appl Phys 39:685692. https://doi.org/10.1088/0022-3727/39/4/014

29. Zhou J, Tsai HL, Lehnhoff TF (2006) Investigation of transport phenomena and defect formation in pulsed laser keyhole welding of zinc-coated steels. J Phys D Appl Phys 39(24):5338-5355. https://doi.org/10.1088/0022-3727/39/24/036

30. Rońda J, Siwek A (2011) Modelling of laser welding process in the phase of keyhole formation. Arch Civ Mech Eng 11(3):739752. https://doi.org/10.1016/S1644-9665(12)60113-7

31. Zhou J, Tsai HL, Wang PC (2006) Transport phenomena and keyhole dynamics during pulsed laser welding. Trans Am Soc Mech Eng 128(July):680-690. https://doi.org/10.1115/1.2194043

32. Svenungsson J, Choquet I, Kaplan AF (2015) Laser welding process - a review of keyhole welding modelling. Physics Procedia 78(August):182-191. https://doi.org/10.1016/j.phpro.2015.11. 042
33. Gladush GG, Smurov I (2011) Physics of laser materials processing. Springer, Berlin

34. Sandvik (2018) Austenitic Stainless Steel Metal Powder. https://www.materials.sandvik/en/products/metal-powder/list-ofmaterials/austenitic-stainless-steels/, Accessed 30-08-2018

35. Cowan RD (1963) Pulse method of measuring thermal diffusivity at high temperatures. J Appl Phys 34(4):926-927

36. Smakula A, Sils V (1955) Precision density determination of large single crystals by hydrostatic weighing. Phys Rev 99(6):17441746

37. ASTM (2015) Standard terminology for additive manufacturing general principles. Part 1: Terminology. ISO/ASTM Stand 52792, ASTM

38. (1994) DIN 51007 Thermal analysis; differential thermal analysis; principles. STANDARD by Deutsches Institut Fur Normung E.V. (German National Standard)

39. Mills K (2002) Recommended values of thermophysical properties for selected commercial alloys. Woodhead publishing limited, Cambridge. https://doi.org/10.1016/B978-1-84569-990-1. 50021-1

40. Trapp J, Rubenchik AM, Guss G, Matthews MJ (2017) In situ absorptivity measurements of metallic powders during laser powder-bed fusion additive manufacturing. Appl Mater Today 9:341-349. https://doi.org/10.1016/j.apmt.2017.08.006

41. King WE, Barth HD, Castillo VM, Gallegos GF, Gibbs JW, Hahn DE, Kamath C, Rubenchik AM (2014) Observation of keyhole-mode laser melting in laser powder-bed fusion additive manufacturing. J Mater Process Technol 214(12):2915-2925. https://doi.org/10.1016/j.jmatprotec.2014.06.005

42. Hann DB, Iammi J, Folkes J (2011) A simple methodology for predicting laser-weld properties from material and laser parameters. J Phys D Appl Phys 44(44):1-9. https://doi.org/10.1088/0022-3727/44/44/445401

43. Scipioni Bertoli U, Wolfer AJ, Matthews MJ, Delplanque JPR, Schoenung JM (2017) On the limitations of volumetric energy density as a design parameter for selective laser melting. Mater Des 113:331-340. https://doi.org/10.1016/j.matdes.2016.10.037 